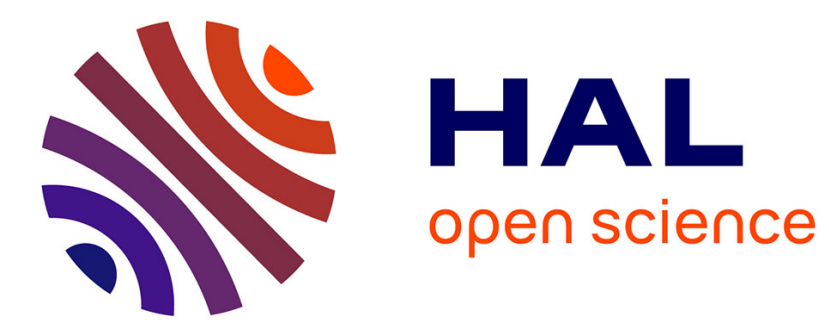

\title{
Optimization of source-sink dynamics in plant growth for ideotype breeding: a case study on maize
}

Rui Qi, Yuntao Ma, Baogang Hu, Philippe de Reffye, Paul-Henry Cournède

\section{To cite this version:}

Rui Qi, Yuntao Ma, Baogang Hu, Philippe de Reffye, Paul-Henry Cournède. Optimization of sourcesink dynamics in plant growth for ideotype breeding: a case study on maize. Computers and Electronics in Agriculture, 2010, 71 (1), pp.96-105. 10.1016/j.compag.2009.12.008 . hal-00493526v3

\section{HAL Id: hal-00493526 \\ https://hal.science/hal-00493526v3}

Submitted on 29 Jun 2010

HAL is a multi-disciplinary open access archive for the deposit and dissemination of scientific research documents, whether they are published or not. The documents may come from teaching and research institutions in France or abroad, or from public or private research centers.
L'archive ouverte pluridisciplinaire HAL, est destinée au dépôt et à la diffusion de documents scientifiques de niveau recherche, publiés ou non, émanant des établissements d'enseignement et de recherche français ou étrangers, des laboratoires publics ou privés. 
1 Optimization of source-sink dynamics in plant growth for ideotype breeding: a case

$$
\text { study on maize }
$$

Rui QI ${ }^{a b^{*}}$, Yuntao MA ${ }^{\text {bc }}$, Baogang HU ${ }^{\mathrm{b}}$, Philippe de REFFYE ${ }^{\text {de }}$, Paul-Henry (1) COURNÈDE ${ }^{\text {ad }}$

${ }^{a}$ Ecole Centrale Paris, Laboratory of Applied Mathematics, 92295 Chatenay-Malabry,

France

b Institute of Automation, Chinese Academy of Sciences, LIAMA, Beijing 100080, China

${ }^{\mathrm{c}}$ China Agricultural University, Key Laboratory of Plant-Soil Interactions, Ministry of Education, College of Resources and Environment, Beijing 100094, China

d INRIA saclay Ile-de-France, EPI Digiplant, Parc Orsay Université, 91893 Orsay cedex, France

${ }^{\mathrm{e}}$ CIRAD montpellier, AMAP, 34398, France

Corresponding author: Rui QI

Telephone: (+33) 0141131789

Email address: qiruitree@gmail.com

Fax: (+33) 0141131735 


\section{Abstract}

The objective of this work is to illustrate how a mathematical model of plant growth could be possible to design ideotypes and thus leads to new breeding strategies with optimization guidance. As a test case, maize (Zea mays L., DEA cultivar), which is one of the most widely cultivated cereals all over the world, is selected for this study. The experimental data reported in a previous study are used to estimate parameters of a plant growth model. As the cob and the compartment of leaves and stem can be benefited from economically, an optimization problem with single objective maximization of cob weight and a multi-objective optimization problem are formulated, respectively. The Particle Swarm Optimization approach is applied to solve these two optimization problems based on the existing plant growth model, namely, "GreenLab". The optimized variables are specific parameters of GreenLab model related to plant genetics, specially the parameters of the cob sink variation function. The cob position on the stem is an additional factor in the investigation. Plant growth behavior is analyzed based on the plant growth model through optimizations. The optimization results revealed the source-sink dynamics. In comparison with the experimental data reported in a previous study, the numerical results showed significant yield increasing from both optimization problems. The work described in this paper confirmed that optimization approaches will be a promising tool for genetic analysis and management control to improve breeding strategies and to design an ideotype of high-yield maize, especially in the current agricultural context and the increasing importance of co-products when designing 
1 cultivation practices.

2 Key words: Pareto front, GreenLab, functional-structural model, Zea mays.,

3 multi-objective optimization

\section{Introduction}

In plant breeding, the concept of ideotype is first defined in (Donald, 1968): "a plant model which is expected to yield a greater quantity or quality of ... useful product when developed as a cultivar", "plants with model characteristics known to influence photosynthesis, growth, and (in cereals) grain yield". Since then, the design of ideotype has been a major issue in genetic selection in order to optimize crop yields. There are two main strategies to investigate ideotype breeding: experiment based and plant model based approaches. Peng et al. (2008) presented the research results of almost 20 years on the ideotype design of rice with the objective of high potential yield, using an experiment based approach. However, the performance of the improved plant type, which is obtained after the first five year experiments, is worse and disappointing. The critical drawback of experiment based approach is that the time consuming for experiments is long (10 years needed by Dencic (1994) and by Lauri and Costes (2004)) and it consumes resources that are limited (field, water, labor) due to the cultivation of thousands of plants (Dencic, 1994). Nowadays, it becomes widely accepted that plant growth models may provide efficient tools to study plant growth behavior (Tardieu, 2003; Letort et al., 2008a), since they can not only complement field experiments, but also save time and resources. Therefore, researchers dedicated themselves to study ideotype breeding based on plant models 
1 (Yin et al., 2003; Cilas et al., 2006). As plant architectural information is more

2 intuitionistic and is easier to measure, Cilas et al. (2006) used an architectural plant

3 growth model to study the ideotype of Coffea canephora for good yield capacity. Like

4 as, in Peng et al. (2008), the architecture traits of the ideotype plant were highlighted.

5 Yin et al. (2003) pointed out that the physiological information of plant growth can

6 also be used to improve the ideotype breeding efficiency; hence, he used a process

7 based plant growth model for ideotype breeding. However, note that even though

8 Cilas et al. (2006) and Peng et al. (2008) investigated ideotype breeding from the

9 architectural point of view, and Yin et al. (2003) from the physiological point of view, they all agree that there exist critical relationships between plant architectures and

11 physiological processes during plant growth, with other researchers like Rasmusson 
1 vegetative compartment can be used as biofuel of the first and second generations,

2 respectively, which becomes of important economical interest (Baenziger et al., 2006).

3 Therefore, the objective of this work is to breed maize first with the potential best cob

4 yield, and second with high yields of both cob and vegetative compartments. To find

5 the appropriate ideotype of maize that satisfies the requirement of high yield capacity,

6 optimization problems with respect to plant physiological processes are formulated

7 and numerical optimization methods are applied to a functional-structural plant

8 growth model.

There have been a lot of works about optimization on crops based on plant growth models in the past decades. Most of the corresponding works are related to

11 optimization of environmental components including water (Ho et al., 2004), soil 12 (Mustafa, 1989) or temperature (Fink, 1993); others related to optimization of 13 cultivation modes, such as fertilizer (van Evert et al., 2006), seeding strategy

14 (Prasanna Kumar et al., 2008) or water supply strategy (Wu et al., 2005). Moreover,

15 several works focused on optimizing climate conditions especially in greenhouse 16 (Linker et al., 1998; Dieleman et al., 2006; van Henten et al., 2006). Morimoto et al. 17 (1993) also did optimal control of water supply (Morimoto et al., 1995), humidity 18 (Morimoto et al., 1997) and temperature control (Morimoto et al., 2003) on plant 19 growth. But the plant growth model he used is a kind of "black-box", which is trained 20 and formed by neural networks, without using physiological mechanisms of plant 21 growth. The corresponding review about optimization on environmental factors can 22 be found in (van Straten et al., 2000; King and Sigrimis, 2001; Ferentinos et al., 2006). 
1 Technically and generally speaking, all of these optimization works belong to optimal

2 control. Even though Haverkort and Grashoff (2004) and Herndl et al. (2007) used

3 plant models to find the ideotype of plants with the optimum product with respect to

4 physiological parameters, the results they found were through trial and error method

5 based on simulation. None of them did optimization on the parameters that describe

6 the inner physiological processes of plant growth, the factors related to genetic

7 parameters or new genotype investigations for a specific species. physiological processes (Mathieu et al., 2008) that is necessary for ideotype breeding. Second, Preliminary studies have allowed modelling the growth of maize cultivars with the GreenLab model. Model parameters had already been estimated from experimental data over different years (Guo et al., 2006; Ma et al., 2007) and over probable link of the model parameters to the genotype of the species. Letort et al. 
1 parameters have been well estimated on tomato (Dong et al., 2008), chrysanthemum

2 (Kang et al., 2006), wheat (Kang et al., 2008), cucumber (Mathieu et al., 2007),

3 Chinese pine tree (Guo et al., 2006), Arabidopsis (Letort et al., 2006), and beech tree

4 (Letort et al., 2008b). GreenLab model was shown to be an efficient tool to describe

5 source-sink dynamics in plant growth. Fourth, GreenLab model can be considered as

6 a dynamic system, whose mathematical formulation makes it suitable for solving

$7 \quad$ optimization problems.

As mentioned above, from an economical point of view, there are potential

9 benefits from both cob weight and the total weight of leaves and stem (to feed animals

10 as forage, or biofuel). Firstly, an optimization problem with single objective

11 maximization of cob weight is formulated and investigated, as the most beneficial

12 component in maize is cob. And then, a multi-objective optimization problem with

13 two conflict objectives: maximization of cob weight and of the total weight of

14 vegetative compartment at the same time, is formulated with a constraint of a minimal

15 tassel weight. The optimization is based on the GreenLab plant growth model, which

16 is used to simulate the growth behavior of maize and to estimate parameters from

17 measured data which are the preconditions of applying optimization. It is

18 acknowledged that cob weight is highly dependent on growth conditions during the

19 early stages of grain filling and the final cob weight reflects the source-sink ratio of

20 the entire grain filling period (Borrás et al., 2002); final cob weight of maize depends

21 on the relationship between cob sink and availability of assimilates resulting from the 
1 optimized variables of both problems are specific GreenLab parameters related to

2 plant genetics: parameters of cob sink variation function. In addition, the impact of

3 cob position on the cob weight and on the total weight of vegetative compartment is

4 investigated. A heuristic optimization algorithm, Particle Swarm Optimization (PSO)

5 was used to solve the problems.

6

7

\section{Materials and method}

\section{Description of the GreenLab model}

GreenLab is a functional-structural plant growth model combining the descriptions of plant architecture and physiological processes of plant growth, in interaction with the environment (light, water, temperature and density). The dynamic mechanisms to generate plant architecture (organogenesis), plant biomass production and partitioning to the organs are introduced in details in (de Reffye and Hu, 2003; Yan et al., 2004; Cournède et al., 2008). Here, only the necessary points to understand our approach are recalled.

In the usual cultivation conditions, maize is a single stem crop. The phytomer appearance is controlled by the thermal time in GreenLab model for maize. The model time step, also called growth cycle (GC), is thus equivalent to the thermal time necessary for a new phytomer to appear. The topology of maize cultivar ND108 is simplified as follows: first six phytomers with short internodes appear; they are followed by 15 phytomers with longer internodes; the last one bears the male flower (tassel). Therefore, the organogenesis terminates at the end of the $21^{\text {st }}$ growth cycle, 
1 but the plant is still alive until the $33^{\text {rd }}$ growth cycle. Even though several phytomers

2 may bear female flowers (cobs), Guo et al. (2006) chose to gather all the potential cob

3 weights on the $15^{\text {th }}$ phytomer. This simplification was proved very effective for plant

4 modelling and model calibration (Guo et al., 2006).

5 The functional processes of plant growth are described by a source-sink model in

6 GreenLab, with a common pool of biomass. GreenLab simulates plant growth from

7 the seed stage, hence the initial plant biomass is from seed and the initial organs are

8 driven by seed. And then, at the following growth cycle $n$, biomass production $Q_{n}$ of

9 an individual plant is described in Eqn.(1). It depends on the total green leaf surface

10 area at the end of the previous growth cycle $n-1\left(S_{n-1}\right)$, on environmental factors

11 gathered in the function $E_{n}$ and on empirical parameters $\beta$ (linked to energetic

12 efficiency) and $\gamma$ (linked to light interception):

$$
\begin{aligned}
& Q_{n}=\beta E_{n}\left(1-\exp \left(-\gamma S_{n-1}\right)\right) \\
& Q_{0}=Q_{\text {seed }}
\end{aligned}
$$

where $Q_{\text {seed }}$ is seed biomass.

All living organs (blades, sheaths, internodes, cob and tassel) are sinks among

16 which biomass is distributed according to their sink values. The total demand of the

17 plant at growth cycle $n$, denoted by $D_{n}$, is given by:

$$
D_{n}=\sum_{o} \sum_{j=1}^{\min \left(n, t_{x_{-}}{ }^{o}\right)} N_{n-j+1}^{o} p_{o}(j)
$$
where $p_{o}(j)$ is the sink of organ $o$ with age $j ; o$ represents blade $(a)$, sheath $(s)$, internode $(e)$, female $(f)$ and male $(m)$ organs; $t_{x_{-} o}$ is the expansion duration of organ $o$; $21 \quad N_{n}^{o}$ is the number of organ $o$ generated at growth cycle $n$. 
The biomass increment of an organ $o$ with age $j$ at growth cycle $n$ is proportional

to its sink value $p_{o}(j)$ and the ratio of biomass production to the total demand of the plant, as detailed in Eqn.(3).

$$
\Delta q_{o}(n, j)=p_{o}(j) \frac{Q_{n}}{D_{n}}
$$

The accumulated biomass for an organ $o$ with age $j$ at growth cycle $n$ is given by:

$$
q_{o}(n, j)=\sum_{k=1}^{j} \Delta q_{o}(n-j+k, k)
$$

As a consequence, the total green leaf surface area at growth cycle $n$, denoted by $S_{n}$, is

$$
S_{n}=\frac{\sum_{j=1}^{t_{a}} N_{n-j+1}^{a} \cdot q_{a}(n, j)}{s l w}
$$

where $t_{a}$ is the blade functioning duration, and $s l w$ is the specific leaf weight.

The family of Beta functions was chosen to describe the sink variation during the expansion, as in Eqn.(6).

$$
\begin{aligned}
& f_{o}(j)=\left\{\begin{array}{ll}
b e_{o}(j) / M_{o} & \left(1 \leq j \leq t_{x_{-} o}\right) \\
0 & \left(j>t_{x_{-} o}\right.
\end{array}\right) \\
& \text { with } b e_{o}(j)=(j-0.5)^{a_{o}-1} \cdot\left(t_{x_{-} o}-j+0.5\right)^{b_{o}-1} \\
& \text { and } M_{o}=\max _{j}\left(b e_{o}(j), 1 \leq j \leq t_{x_{-} o}\right)
\end{aligned}
$$

where $a_{o}$ and $b_{o}$ are the coefficients of the sink variation function.

The sink value of an organ with age $j$, denoted by $p_{o}(j)$, is $f_{o}(j)$ multiplied by the sink amplitude (also called sink strength) $P_{o}$ as in Eqn.(7). Diverse sink variations can be obtained by setting different values of the coefficients: $a_{o}$ and $b_{o}$ in Eqn.(6). An example is given in Figure 1. 


$$
p_{o}(j)=P_{o} f_{o}(j)
$$

\section{Field experiment and field measurements on maize}

Maize cultivar ND108 (Zea mays L., DEA cultivar) seed was sown 0.6 m apart

5 in north-south-oriented rows that were $0.6 \mathrm{~m}$ apart, at the China Agricultural

6 University $(\mathrm{CAU})\left(39^{\circ} 50^{\prime} \mathrm{N}, 116^{\circ} 25^{\prime} \mathrm{E}\right)$. The resulting plant population (28 000 plants

$7 \mathrm{ha}^{-1}$ ) is about half that commonly used by local farmers and was chosen to minimize

8 competition among plants. Plants emerged on the 18th May 2000. Soil, irrigation and

9 fertilizer inputs were managed so as to avoid any mineral and water limitation to plant

10 growth, and plant disease, pest or stress symptoms. Samples were taken destructively

11 on 12 dates. Fresh weights of blades, sheaths, internodes, cob and tassel were

12 measured and recorded individually at each sample date. The number of organs

13 generated at each growth cycle, the functioning duration of blades and the expansion

14 duration of organs, specific leaf weight, can be observed and measured by field

15 experiments. The detailed information about the environmental conditions, sampling

16 strategy and the measured data is given by (Guo et al., 2006).

\section{Parameter estimation of GreenLab}

In GreenLab, the parameters are classified into two categories: measurable

19 parameters, i.e. functioning duration of blades, number of organs emerged at each

20 growth cycle, and hidden parameters which cannot be measured directly in the field,

21 i.e. organ sink. To guarantee that GreenLab can describe the dynamic processes of 22 plant growth well, it is necessary to estimate the hidden parameters through 
1 minimizing the difference between the measured data and the corresponding

2 simulation results of GreenLab.

5 this paper, the data measured at three stages $\left(8^{\text {th }} \mathrm{GC}\right.$ corresponding to vegetative stage,

$618^{\text {th }} \mathrm{GC}$ approximately corresponding to flowering stage and $33^{\text {rd }} \mathrm{GC}$ corresponding

The same set of parameters is estimated simultaneously by fitting with several plants of a species at different development stages, which is called multi-fitting. In to physiological maturity) are used as target data.

\section{Multi-objective Optimization}

In multi-objective optimization problems, several objectives are optimized (maximization or minimization) simultaneously. The mathematical formulism of a multi-objective optimization problem is given by:

$$
\begin{aligned}
& \text { Maximize }\left(J_{1}, J_{2}, \cdots, J_{m}\right) \\
& \text { s.t. } \\
& \quad g_{i}\left(x_{1}, x_{2}, \cdots, x_{n}\right) \leq 0, \quad i=1,2, \cdots, k \\
& \quad h_{j}\left(x_{1}, x_{2}, \cdots, x_{n}\right)=0, \quad j=1,2, \cdots, l .
\end{aligned}
$$

where $x_{i}$ is the $i$ th element of the vector $\boldsymbol{X}$ on which we optimize and $n$ is the dimension of the problem; $J_{i}$ is the $i$ th objective which is a function of $\boldsymbol{X}$ and $m$ is the number of objectives; $g_{i}$ is the $i$ th inequality constraint of the problem and $k$ is the number of inequality constraints; $h_{j}$ is the $j$ th equality constraint and $l$ is the number of equalities.

For multi-objective optimization problems, generally, objectives are in conflict with each other. In comparison with single objective optimization problems for which we may have results on the existence and unicity of the solution, the situation of multi-objective problems is more complex, since there is no canonical relationship in 
1 the feasible space. Thus, the optimal solutions for multi-objective optimization

2 problems is defined such that for these solutions, performance on one objective cannot

3 be improved without sacrificing performance on at least another. The solutions

4 satisfying this property form the Pareto front (Mostaghim and Teich, 2003).

5 For maize, one of our objectives is to maximize cob weight, which is used for

6 food or biofuel of the first generation. The formula for calculating the final weight of

7 cob when plant age is $n$ is as follows:

8

9

$$
J_{1}=\sum_{k=1}^{t_{x} f} p_{f}(k) \frac{Q_{n-\left(t_{x-f}-k\right)}}{D_{n-\left(t_{x-f}-k\right)}}
$$

However, for the cultivar of maize ND108 (Zea mays L., DEA cultivar) that we considered, leaves and stems are useful for poultry as a kind of forage. Moreover, leaves and stem of maize will be also used for biofuel of the second generation, whereas cob should be reserved for food. Thus, it is also of economical interest to maximize the total weight of leaves and stem. The equation for calculating the final weight of leaves and stem is given by:

$$
J_{2}=\sum_{j=1}^{n} N_{n-j+1}^{a} \sum_{k=1}^{\min \left(j, t_{x_{-}}\right)} p_{a}(k) \frac{Q_{n-j+k}}{D_{n-j+k}}+\sum_{j=1}^{n} N_{n-j+1}^{i} \sum_{k=1}^{\min \left(j, t_{x_{-}}\right)} p_{i}(j) \frac{Q_{n-j+k}}{D_{n-j+k}}
$$

In Eqn.(10), the first item corresponds to the total weight of leaves, and the second item to the stem weight.

A constraint on the tassel weight is also imposed, since cob weight and tassel weight are interrelated. Cob weight is controlled by pollen production, while the pollen production depends on the tassel size of maize. Uribelarrea et al. (2002) showed that if the tassel size is reduced, the cob size will be limited. Thus, a 
1 constraint that the tassel weight should be beyond a threshold is set. The formula for

2 calculating the final weight of tassel when plant age is $n$ is as follows:

$$
g=\sum_{k=1}^{t_{x_{-}} m} p_{m}(k) \frac{Q_{n-\left(t_{x_{-} m}-k\right)}}{D_{n-\left(t_{x_{-}-m}-k\right)}}
$$

Finally, the multi-objective optimization for maize is given by:

$$
\begin{aligned}
& \text { Maximize }\left(J_{1}, J_{2}\right) \\
& \text { s.t. } g \geq \text { threshold }
\end{aligned}
$$

For potential applications in breeding, the parameters we optimize should be linked to plant genetics and therefore should be representative of some physiological processes. As it is acknowledged that final cob weight of maize depends on the relationship between cob sink and biomass production (Borrás et al., 2002), we choose to study the cob sink variation. Thus, the parameters we optimize are the cob sink strength $P_{f}$ and the two coefficients of the Beta function $a_{f}$ and $b_{f}$. The effect of cob position on the cob weight and on the total weight of leaves and stem is also studied.

\section{Particle Swarm Optimization (PSO)}

The optimization problem revealed non convex and multimodal, particularly since there is no unique solution for multi-objective problems. Therefore, population-based heuristic optimization algorithms, which usually allow obtaining quickly a number of acceptable solutions, were used in our study. Compared to the other population-based heuristic optimization algorithms, PSO has a high convergence rate for a wide range of optimization problems (Kennedy and Eberhart, 
1 2001). Hence, it was chosen to solve our problems. PSO is proposed by Kennedy and Eberhart (1995), which originally simulates the behaviour of bird flocking. It is also an iterative algorithm, similar to other population-based optimization algorithms. The feasible solutions found at the current iteration are recorded separately in each individual in the population as their current positions. The direction and the distance controlling how the individuals move are determined by their velocities and their experiences during the searching. With the help of social and cognition knowledge of each individual (also called particle), the population (also called swarm) converges to the optimal solution (or position). With the increasing development of PSO in the past decade, there are many variants of PSO in order to improve its performance (convergence rate, convergence accuracy, etc). In this paper, PSO with passive congregation (He et al., 2004) is used to solve the single objective optimization problem, thanks to its generalization capacities and robust performance. The equations used to calculate velocities and the new positions are given by:

$$
\begin{aligned}
& v_{i j}^{k+1}=\omega^{k} v_{i j}^{k}+c_{1} r_{1}\left(B_{i j}-x_{i j}^{k}\right)+c_{2} r_{2}\left(B_{g j}-x_{i j}^{k}\right)+c_{3} r_{3}\left(B_{r j}-x_{i j}^{k}\right) \\
& x_{i j}^{k+1}=x_{i j}^{k}+v_{i j}^{k+1}
\end{aligned}
$$

7 where $v_{i j}{ }^{k}$ is the $j$ th coordinate of the velocity of the $i$ th particle at iteration $k ; B_{i j}$ is the 8 th coordinate of the best position recorded by the $i$ th particle during the previous 9 iterations; $B_{g j}$ is the $j$ th coordinate of the position of the global best particle among all the particles in the swarm, which is marked by $g ; B_{r j}$ is the $j$ th coordinate of the best position recorded by a random selected particle $r$ during the previous iterations; $x_{i j}{ }^{k}$ is the $j$ th coordinate of the current position of particle $i$ at iteration $k$; $w^{k}$ is inertia weight 
1 value at iteration $k$, which decreases linearly from the maximal inertia weight to the

2 minimal one; $c_{1}$ and $c_{2}$ are acceleration coefficients; $r_{1}$ and $r_{2}$ are uniformly distributed

3 random values between 0 and 1 . The second and the third items of Eqn. (13) on the

4 right hand side are considered as cognition knowledge and social knowledge of a

5 particle respectively, and the last item is used to avoid getting trapped into the local

6 optimum.

Many researchers have already applied PSO to solve multi-objective optimization problems (Fieldsend, 2004). The specific algorithm that we used is the mixture of the algorithms proposed by Mostaghim and Teich (2003) and by Tripathi et al. (2007). To extend the original PSO to solve multi-objective problem and to find the Pareto front, the equations for changing the velocity and position of each particle are improved slightly, as given by Eqn.(14).

$$
\begin{aligned}
& v_{i j}^{k+1}=\omega^{k} v_{i j}^{k}+c_{1}^{k} r_{1}\left(B_{i j}-x_{i j}^{k}\right)+c_{2}^{k} r_{2}\left(B l_{i j}-x_{i j}^{k}\right) \\
& x_{i j}^{k+1}=x_{i j}^{k}+v_{i j}^{k+1}
\end{aligned}
$$

To make the balance between exploration and exploitation, the acceleration coefficient $c_{1}{ }^{k}$ decreases linearly, and the acceleration coefficient $c_{2}{ }^{k}$ increases linearly. For the problems with constraints, there are two criteria to decide whether the $j$ th coordinate of the best position of each particle $B_{i j}$ is updated by the $j$ th coordinate of the new position $x_{i j}{ }^{k+1}$ : if $x_{i}{ }^{k+1}$ satisfies the constraints while $B_{i}$ does not, or if one of the objective function value with respect to $x_{i}^{k+1}$ is better than the one with respect to $B_{i}$, no matter whether the constraints are satisfied, replace $B_{i j}$ with $x_{i j}{ }^{k+1}$.

The aim of multi-objective optimization problems is to find all the optimal solutions that form the Pareto front. Therefore, to obtain various solutions at a given 
1 iteration, the algorithm is changed by replacing the unique global best position with a

2 local guide best position for each particle, denoted by $B l_{i j}$ for the $j$ th coordinate of 3 particle $i$ in Eqn.(14).

All the optimal solutions are recorded in an archive with limited size. The Sigma method (Mostaghim and Teich, 2003) is used to determine the local guide best position of each particle. The solution in the archive which has the nearest distance from a given particle is decided to its local guide best position. For more details, we refer to (Mostaghim and Teich, 2003). When the maximal number of solutions in the archive is reached, the solutions which have the shortest distance from the other solutions in the archive will be deleted. If the number of solutions in the archive is less than its maximal number, new optimal solutions will be added into the archive.

\section{Results}

\section{Multi-fitting results}

The hidden parameters estimated by a generalized non-linear least square method are different from the ones in Guo et al. (2006) and Ma et al. (2007), as the sink variation function (Beta function) in this work is slightly improved as shown in Eqn.(6). The comparison of the simulation results by GreenLab with the estimated parameters and the measured data is given in Figure 2. The optimization results in the following sections are based on the maize modelled by GreenLab with the estimated parameter values listed in Table 1.

\section{Single optimization problem of maximization of cob weight}


Fixing cob expansion duration, on one hand, it limits the potential duration of obtaining biomass for cob. On the other hand, cob potential ability to obtain biomass will be missed. To avoid these two drawbacks, in this subsection, we suppose that cob expansion duration depends on its position on the stem, to ensure that the cob has possibility to obtain biomass until the end of the plant growth. For example, if the cob appears at the $19^{\text {th }}$ growth cycle, its expansion duration is 15 growth cycles with plant age 33 growth cycles.

The maximal cob weights associated to different cob positions are not significantly different, as shown in Figure 3(a). The corresponding optimal cob sink strength variations are similar as shown in Figure 3(b) marked only with symbols, and the estimated one is represented by the curve in "-.o-". Wherever the cob is and whatever its expansion duration is, we found that the optimal cob development strategies are similar. The optimal cob sink is almost zero at the beginning of cob development, in order to reduce the competition for biomass with source organs and to let leaf surface area increase, and then the sink increases monotonously till the end of plant growth.

Comparing the estimated and optimal cob sink variations with cob particularly born by the $1^{\text {st }}$ phytomer counted from the bottom shown in Figure 3(b), we can separate the cob development process into 4 stages. During the first stage from the $1^{\text {st }}$ growth cycle to $15^{\text {th }}$ growth cycle, the optimal cob sink is a little larger than the estimated one, but can be neglected. It has no negative effect on the source organ development. In this period, the leaf surface areas for the estimated plant and the 
1 optimal plant are the same. Consequently, there is no difference among the optimal

2 cob weights when the cob is born by the $1^{\text {st }}$ phytomer to by the $15^{\text {th }}$ phytomer;

3 meanwhile, it leads to a slight difference among the optimal cob weights when the cob

4 position is higher than the $15^{\text {th }}$ phytomer, as shown in Figure 3(a). The second stage is

5 from the $16^{\text {th }}$ growth cycle to the $23^{\text {rd }}$ growth cycle. Even though the optimal cob sink

6 is still a little larger than the estimated one, it does affect the source organ

7 development. The cob competes for biomass against the source organ and the other

8 organs. This competition leads to the decrease of the leaf surface area as shown in

9 Figure 4. During the third stage from the $23^{\text {rd }}$ growth cycle to the $31^{\text {st }}$ growth cycle,

10 the optimal cob sink value keeps increasing, but smoothly. On the contrary, for the

11 observed plant, the cob sink increases significantly, biomass allocation to the cob is

12 done with detriment to leaves. Hence, the leaf surface area begins to decrease. During

13 the last stage of plant growth within two growth cycles, the optimal cob sink begins to

14 increase significantly and quickly. Since the other organ sinks are negligible, all the

15 biomass is allocated to the cob as shown in Figure 5: the ratio in this period tends to 16 infinity.

17 The comparison results of the cob sink variation reveal the source-sink dynamics.

18 The increment of the cob weight is the product of the cob sink value and the ratio of

19 the plant biomass production, which depends on the leaf surface area, to the plant

20 demand that is the sum of all the organ sinks, as described in Eqn.(3). Even though the

21 cob sink value is smaller than the estimated one, the leaf surface area is higher. Due to the optimal trade-offs between sources and sinks, the cob weight with the optimal 
1 parameter values (1032 $\mathrm{g}$ ) is bigger than the observed one (895 $\mathrm{g})$.

\section{Multi-objective optimization problem}

Economically speaking, we can benefit both from cob as food for human beings and as biofuel of the first generation, and from leaves and stem as forage for poultry and probably as biofuel of the second generation. Therefore, an optimization problem with two objective functions on maximization of cob weight and total weight of leaves and stem simultaneously is investigated. The optimal result of this multi-objective optimization problem, known as Pareto front, is shown in Figure 6, for each cob position. There is no obvious difference among the Pareto fronts associated to each cob position. They are all very similar and can not be distinguished, as shown in Figure 6. Each Pareto front is given by about 500 optimal solutions of cob sink variation. Hence in Figure 7, we outlined the area covered by all the optimal solutions of cob sink variation. Particularly, two examples of the optimal cob sink variation are given, when the cob is born by the $12^{\text {th }}$ phytomer with cob weight of 792 $\mathrm{g}$ and total weight of leaves and stem of $1695 \mathrm{~g}$, and when the cob is born by the $15^{\text {th }}$ phytomer with cob weight of $503 \mathrm{~g}$ and total weight of leaves and stem of $2050 \mathrm{~g}$, respectively.

The Pareto front of our multi-objective optimization problem reveals source-sink dynamics and the necessary balance between both objectives. Maximization of the total weight of leaves and stem leads to a zero cob sink strength. On the other hand, to maximize the cob weight, the cob sink value can not be maximal all the way, otherwise there would not be enough leaf surface area, and the reduced biomass 
1 production would decrease the final cob weight. For this reason, the left extremity of

2 the Pareto front corresponds to a zero cob weight whereas the right extremity

3 corresponds to a strictly positive weight of stem and leaves. For maize cultivar

4 ND108 (Zea mays L., DEA cultivar), the tassel appears and begins to develop at the

$521^{\text {st }}$ growth cycle, with a very quick expansion (2 growth cycles). From the optimal

6 results shown in Figure 7, we found that the tassel expansion corresponds to the early

7 stages when the cob sink begins to increase.

In Figure 8, the evolution of the tassel weight corresponding to the points on the

9 Pareto front is illustrated. We see that for a wide range, the tassel weight does not

10 vary since its expansion corresponds to growth cycles when the cob sink is still very

11 low. However, we found that for the maximal cob weights (above 900g), the tassel

12 weight is decreasing. It corresponds to experimental observations of Westgate et al.

13 (2003) who indicated that there is a potential gain of cob yield by decreasing the tassel

14 weight.

The cob weight simulated by GreenLab with the estimated parameter values is $1013 \mathrm{~g}$, whereas the total weight of leaves and stem is $927 \mathrm{~g}$ and the tassel weight is $29 \mathrm{~g}$. With the optimal parameter values, the maximal cob weight among the Pareto front in Figure 6 is $1032 \mathrm{~g}$, the corresponding total weight of leaves and stem is $955 \mathrm{~g}$ and the tassel weight is $30 \mathrm{~g}$. Comparing the Harvest Index (HI) of the simulated and the optimal plants, HI of the optimal one is surprisingly a little smaller than the simulated one, even though both the cob weight and the total weight of leaves and stem are higher than the simulated one. It revealed the trade-offs between sources and 
1 sinks. Post-expansion and fast growing rate as shown in Figure 3(b) and Figure 7 will not only enhance the cob weight but also the weight of leaves and stem.

\section{Discussion}

In this paper, we have illustrated how the optimization of the parameters of plant growth models could be used to design ideotypes for genetic selection. The GreenLab model was chosen for the simplicity of its parameterization. Moreover, it describes plant growth, both from ecophysiological and architectural points of view, at the individual organ scale, which potentially allows distinguishing more easily genetic and environmental effects. However, we should note that the model can be extrapolated to stand level by taking into account competition between individuals (Cournède et al., 2008).

Particle Swarm Optimization (PSO), which is a population-based heuristic optimization algorithm, is used to solve the single and multi-objective optimization problems. As it does not require the differentiation of the objective functions, and it returns several solutions at the same time, we can benefit from it to solve non-convex, single objective or multi-objective optimization problems, with potentially non-unique solutions. Compared to other population-based heuristic optimization algorithms, such as Genetic Algorithm, the PSO has a high convergence rate and a better accuracy (Kennedy and Eberhart, 2001). Even though the optimal solutions found by the PSO cannot be proven to be global, the results are better than observations and can be used to practically guide genetic selection. 
The sink variation function corresponding to the maximal cob weight reveals the optimal source-sink dynamics. In order to obtain the maximal yield of cob, the cob sink value keeps extremely small: almost zero during the early development stages, so that the leaf surface area may increase. When biomass production almost saturates, the cob begins absorbing biomass quickly, especially during the last several growth cycles where nearly all the available biomass is allocated to the cob and the cob becomes the strongest competitor for biomass against the other organs. This phenomenon can be derived from the monotonously increasing cob sink variation as illustrated in Figure 3(b) for the single objective optimization of maximization of cob weight and in Figure 7 for the optimal solutions of the multi-objective optimization problem. This optimal cob development strategy is in agreement with Weiner (1988) and Vega et al. (2000): there is a threshold size for plants to produce flowers and fruits, the plant will grow as much as it can until its biomass reaches a threshold, and then the biomass may be distributed to fruits and flowers.

The interaction between cob and tassel is also deduced from the single and multi-objective optimization problems. The optimal solutions of cob sink variation revealed that the cob growth requires pollen which is provided by tassel. To get better cob weight, cob begins to absorb biomass mainly from the $20^{\text {th }}$ growth cycle, while the tassel appears and absorbs biomass at the $21^{\text {st }}$ growth cycle, and stops growing one growth cycle later, i.e. at the $22^{\text {nd }}$ growth cycle. Considering this strong interaction between cob and tassel (Borrás et al., 2002; Uribelarrea et al., 2002), tassel weight is integrated into our multi-objective optimization problem as a constraint. A threshold is 
1 set for tassel weight (not less than $10 \mathrm{~g}$ ). In contrary to optimal solutions of general

2 optimization problems with constraints that are on the boundary of the feasible area

3 formed by constraints, all the tassel weights are higher than this $10 \mathrm{~g}$. One reason is

4 that so far we do not know the relationship between cob and tassel quantitatively.

5 Hence, it is difficult to set the threshold value. Another reason is that tassel sink

6 strength variation is fixed and it does not change according to the cob sink strength

7 variation, in this work.

8 From the optimal results, the ideotype of maize can be deduced. From a

9 physiological point of view, the cob begins to absorb biomass from about the $20^{\text {th }}$

10 growth cycle when the leaf area saturates, independently of the cob position. And then,

11 it absorbs biomass smoothly or significantly, depending on the breeding objectives.

12 Especially, if the objective is to have a maximal cob weight, the maize should have a bigger reproductive capacity, and the cob should grow with post-expansion and fast

14 growth rate. From an architectural point of view, for the maize giving the maximal

15 cob weight, the leaf size is reduced during the last vegetative and reproductive stages

16 of growth. The harvest index is above $50 \%$. It is coincident with the ideotype of maize

17 proposed by Mock and Pearce (1975) by analysing research results of other people

18 with experimental based approach. The Pareto front of the multi-objective

19 optimization problem presents all the different optimal strategies, and the

20 decision-maker could choose his optimal strategy according to market prices or the

21 application purposes for example. The optimal results provide a reference to improve breeding strategies and to design a new ideotype of maize. 
Even though GreenLab model can simulate plant growth in response to environmental conditions (light, temperature, water, competition), some complementary work is needed to describe simultaneously carbon balance and water balance that determine the distinction between fresh and dry biomass. In addition, the parameters that we optimized are oriented to those related to the cob sink variation function, whereas the others are fixed to be the estimated values. However, there might be some correlation between parameters. Due to the limited observation data (samples), we have not been able to assess the correlation between parameters so far. If these drawbacks are corrected correspondingly, the parameter estimation accuracy should be increased and the frame work for optimization shall be improved. If the estimated parameter values are changed, the optimal solutions may be different, as the optimization is based on the model with estimated parameters. However, the methodology that we proposed to maximize both cob weight and the vegetative compartment weight, is still valid. Furthermore, it is interesting to note that the relationship between sources and sinks as illustrated in Figure 3(b) and Figure 7 does not depend on parameter values. The qualitative results are not changed.

Actually, in cobs, only kernels give the food for human beings or for livestock. The number of kernels is a critical factor that affects the final kernel weight (Borrás and Otegui, 2001). Therefore, optimizing the number of kernels per cob could be an interesting work in future. So far, we do not have the information about the proportion of the kernel weight to the cob weight, which raises the difficulty to estimate parameters of GreenLab model. However, the corresponding experimental work is in 
1 process this year.

2

\section{Conclusion}

Two kinds of optimization problems of either only maximization of cob weight or maximization of cob weight and total weight of leaves and stem simultaneously were formulated. The non-convex, multimodal or non-unique solution problems were solved by a heuristic optimization algorithm, Particle Swarm Optimization.

The source-sink dynamics is investigated through optimization in this study. The optimization results provide a reference for decision-makers to improve the breeding strategies or to design ideotypes of plants, especially in the current context of biofuel development, increase in agricultural products price and necessity to consider co-products when designing cultivation practices.

\section{Acknowledgement}

This work is partly supported by Natural Science Foundation of China (60073007, 60703043), Chinese 863 program (2008AA10Z218), and the French embassy in China.

\section{References}

Allen, M., Prusinkiewicz, P., DeJong, T., 2005. Using L-systems for modeling source-sink interactions, architecture and physiology of growing trees: the L-PEACH model. New Phytologist 166, 869-880. 
1 Baenziger, P.S., Russell, W.K., Graef, G.L., Campbell, B.T., 2006. Improving Lives: 50 years of Crop Breeding, Genetics, and Cytology (C-1). Crop Sci. 46, $2230-2244$.

Borrás, L., Otegui, M.E., 2001. Maize Kernel Weight Response to Postflowering Source-Sink Ratio. Crop Sci. 41, 1816-1822.

Borrás, L., Cura, J.A., Otegui, M.E., 2002. Maize Kernel Composition and Post-Flowering Source-Sink Ratio. Crop Sci. 42, 781-790.

Borrás, L., Westgate, M.E., Otegui, M.E., 2003. Control of Kernel Weight and Kernel Water Relations by Post-flowering Souce-sink Ratio in Maize. Ann. Bot. 91, $857-867$

Carson, E., Feng, D.D., Pons, M.N., Soncini-Sessa, R., van Straten, G., 2006. Dealing with bio- and ecological complexity: Challenges and opportunities. Annual Reviews in Control 30, 91-101.

Cilas, C., Bar-Hen, A., Montagnon, C., Godin, C., 2006. Definition of Architectural Ideotypes for Good Yield Capacity in Coffea canephora. Ann. Bot. 97, 405-411.

Cournède, P.H., Mathieu, A., Houllier, F., Barthélémy, D., de Reffye, P., 2008. Computing Competition for Light in the GREENLAB Model of Plant Growth: A Contribution to the Study of the Effects of Density on Resource Acquisition and Architectural Development. Ann. Bot. 101, 1207-1219.

Dencic, S., 1994. Designing a Wheat Ideotype with Increased Sink Capacity. Plant Breeding 112, 311-317.

Dieleman, J.A., Marcelis, L.F.M., Elings, A., Dueck, T.A., Meinen, E., 2006. Energy 
Saving in Greenhouse: Optimal Use of Climate Conditions and Crop Management. Acta Hort. (ISHS) 718, 203-210.

Donald, C.M., 1968. The breeding of crop ideotypes. Euphytica 17, 385-403.

Dong, Q., Louarn, G., Wang, Y., Barczi, J.F., de Reffye, P., 2008. Does the Structure-Function Model GREENLAB Deal with Crop Phenotypic Plasticity Induced by Plant Spacing? A Case Study on Tomato. Ann. Bot. 101, 1195 1206.

van Evert, F.K., de Visser, P.H.B., Heinen, M., 2006. Operational Optimization of Organic Fertilizer Application in Greenhouse Crops. Acta Hort. (ISHS) 718, $165-172$.

Ferentinos, K.P., Arvanitis, K., Tantau, H., Sigrimis, N., 2006. Special Aspects of IT for Greenhouse Cultivation. In : CIGR Handbook of Agricultural Engineering: Information Technology. American Society of Agricultural and Biological Engineers, St. Joseph, Michigan, pp. 294-312.

Fieldsend, J.E., 2004. Multi-objective particle swarm optimization methods. url=citeseer.ist.psu.edu/735591.html.

Fink, M., 1993. Effects of Short-Term Temperature Fluctuation on Plant Growth and Conclusions for Short-Term Temperature Optimization in Greenhouse. Acta Hort. (ISHS) 328, 147-154.

Fourcaud, T., Zhang, X.P., Stokes, A., Lambers, H., Korner, C., 2008. Plant Growth Modelling and Applications: The Increasing Importance of Plant Architecture in Growth Models. Ann. Bot. 101, 1053-1063. 
1 Guo, H., Letort, V., Hong, L., Fourcaud, T., Cournède, P.H., Lu, Y., de Reffye, P., 2006. Adaptation of the GreenLab Model for Analyzing Sink-Source Relationships in Chinese Pine Saplings. In: Fourcaud, T., Zhang, X.P. (Eds.), Plant growth Modeling, and Applications, IEEE Computer Society (Los Alamitos, California), pp. 236-243.

Guo, Y., Ma, Y.T., Zhan, Zh.G., Li, B.G., Dingkuhn, M., Luquet, D., de Reffye, P., 2006. Parameter Optimization and Field Validation of the Functional-Structural Model GREENLAB for Maize. Ann. Bot. 97, 217-230.

Haverkort, A.J., Grashoff, C., 2004. IDEOTYPING-POTATO a modelling approach to genotype performance. In: MacKerron, D.K.L., Haverkort, A.J. (Eds.), Decision Support Systems in Potato Production - Bringing Models to Pructice, Wageningen Academic Publisher, pp. 199-211.

He, S., Wu, Q.H., Wen, J.Y., Saunders, J.R., Paton, R.C., 2004. A particle swarm optimizer with passive congregation. BioSystems 78, 135-147.

van Henten, E.J., Buwalda, F., de Zwart, H.F., de Gelder, A., Hemming, J., Bontsema, J., 2006. Toward an Optimal Control Strategy for Sweet Pepper Cultivation - 2 . Optimization of the Yield Pattern and Energy Efficiency. Acta Hort. (ISHS) 718, 391-398.

Herndl, M., Shan, C., Wang, P., Graeff, S., Claupein, W., 2007. A Model Based Ideotyping Approach for Wheat Under Different Environmental Conditions in North China Plain. Agricultural Sciences in China 6, 1426-1436.

Ho, M.D., McCannon, B.C., Lynch, J.P., 2004. Optimization modeling of plant root 
architecture for water and phosphorus acquisition. Journal of Theoretical Biology $226,331-340$.

Kang, M., Heuvelink, E., de Reffye, P., 2006. Building Virtual Chrysanthemum based on Sink-source Relationships: Preliminary Results. Acta Hort. (ISHS) 718, $129-136$.

Kang, M., Evers, J.B., Vos, J., de Reffye, P., 2008. The Derivation of Sink Functions of Wheat Organs using the GREENLAB Model. Ann. Bot. 101, 1099 - 1108.

Kennedy, J., Eberhart, R.C., 1995. Particle swarm optimization. In: Proc. IEEE Conf. on Neural Networks, IV, Piscataway, NJ, pp. 1942-1948.

Kennedy, J., Eberhart, R.C., 2001. Swarm Intelligence. Morgan Kaufmann Publishers.

King, R.E., Sigrimis, N., 2001. Computational intelligence in crop production. Computers and Electronics in Agriculture 31, 1-3.

Kurth, W., 2000. Towards universality of growth grammars: Models of Bell, Pagès, and Takenaka revisited. Ann. For. Sci. 57, 543-554.

Lauri, P., Costes, E., 2004. Progress in Whole-Tree Architecture Studies for Apple Cultivar Characterization at INRA, France - Contribution to the Ideotype Approach. Acta Hort. (ISHS) 663, 357-362.

Letort, V., Cournède P.H., Lecoeur, J., Hummel, I., de Reffye, P., Chiustophe, A., 2006. Effect of topological and phenological changes on biomass partitioning in Arabidopsis thaliana inflorescence: a preliminary model-based study. In: Fourcaud, T., Zhang, X.P. (Eds.), Plant growth Modeling, and Applications, IEEE Computer Society (Los Alamitos, California), pp. 65-69. 
1 Letort, V., Mahe, P., Cournède, P.H., de Reffye, P., Courtois, B., 2008a. Quantitative Genetics and Functional-Structural Plant Growth Models: Simulation of Quantitative Trait Loci Detection for Model Parameters and Application to Potential Yield Optimization. Ann. Bot. 101, 1243-1254.

Letort, V., Cournède, P.H., Mathieu, A., de Reffye, P., Constant, T., 2008b. Parametric Identification of a Functional-Structural Tree Growth Model and Application to Beech Trees (Fagus sylvatica ). Functional Plant Biology 35, in press.

Linker, R., Seginer, I., Gutman, P.O., 1998. Optimal $\mathrm{CO}_{2}$ control in a greenhouse modeled with neural networks. Computers and Electronics in Agriculture 19, $289-310$

Luquet, D., Dingkuhn, M., Kim, H., Tambour, L., Clement-Vidal, A., 2006. EcoMeristem, a model of morphogenesis and competition among sinks in rice. 1. Concept, validation and sensitivity analysis. Functional Plant Biology 33, 309-323.

Ma, Y.T., Li, B.G., Zhan, Zh.G., Guo, Y., Luquet, D., de Reffye, P., Dingkuhn, M., 2007. Parameter Stability of the Functional-Structural Plant Model GREENLAB as Affected by Variation within Populations, among Seasons and among Growth Stages. Ann. Bot. 99, 61-73.

Ma, Y.T., Wen, M.P., Guo, Y., Li, B.G., Cournède, P.H., de Reffye, P., 2008. Parameter Optimization and Field Validation of the Functional-Structural Model GREENLAB for Maize at Different Population Densities. Ann. Bot. 101, 1185-1194. 
1 Mathieu, A., Zhang, B.G., Heuvelink, E., Liu, S.J., Cournède, P.H., de Reffye, P., 2007. Calibration of fruit cyclic patterns in cucumber plants as a function of source-sink ratio with the GreenLab model. In: Proceedings of the 5th International Workshop on Functional-Structural Plant Models, Napier, New Zealand, pp. 5-1 - 5-4.

Mathieu, A., Cournède, P.H., Barthélémy, D., de Reffye, P., 2008. Rhythms and Alternating Patterns in Plants as Emergent Properties of a Model of Interaction between Development and Functioning. Ann. Bot. 101, 1233-1242.

Mock, J.J., Pearce, P.B., 1975. An Ideotype of Maize. Euphytica 24, 613-623.

Morimoto, T., Takeuchi, T., Hashimoto, Y., 1993. Growth optimization of plant by means of the hybrid system of genetic algorithm and neural network. In: Neural Networks, IJCNN '93-Nagoya Proceedings of 1993 International Joint Conference on, 3, pp. $2979-2982$.

Morimoto, T., Torii, T., Hashimoto, Y., 1995. Optimal control of physiological processes of plants in a green plant factory. Practice 3, 505-511.

Morimoto, T., De Baerdemaeker, J., Hashimoto, Y., 1997. An intelligent approach for optimal control of fruit-storage process using neural networks and genetic algorithms. Computers and Electronics in Agriculture 18, 205-224.

Morimoto, T., Tu, K., Hatou, K., Hashimoto, Y., 2003. Dynamic optimization using neural networks and genetic algorithms for tomato cool storage to minimize water loss. Trans. ASAE. 46, 1151-1159.

Mostaghim, S., Teich, J., 2003. Strategies for Finding Good Local Guides in 
Multi-objective Particle Swarm Optimization (MOPSO). In: IEEE Swarm Intelligence Symposium, pp. 26-33.

Mustafa, G., 1989. Stochastic dynamic optimization approach for revegetation of reclaimed mine soils under uncertain weather regime. Thesis (Ph.D.), Blacksburg, VA (US), Virginia Polytechnic Institute and State Univ.

Peng, S., Khush, G.S., Virk, P., Tang, Q., Zou, Y., 2008. Progress in ideotype breeding to increase rice yield potential. Field Crops Research 108, 32-38.

Perttunen, J., Sievänen, R., Nikinmaa, E., 1998. LIGNUM: a model combining the structure and the functioning of trees. Ecological Modelling 108, 189-198.

Prasanna Kumar, G.V., Srivastava, B., Nagesh, D.S., 2008. Modeling and optimization of parameters of flow rate of paddy rice grains through the horizontal rotating cylindrical drum of drum seeder. Computers and Electronics in Agriculture, In Press.

Pratt, R.C., 2001. Specialty Corns. Crop Sci. 41, 1990.

Rasmusson, D.C., 1987. An Evaluation of Ideotype Breeding. Crop Sci. 27, 1140-1146.

de Reffye, P., Hu, B.G., 2003. Relevant qualitative and quantitative choices for building an efficient dynamic plant growth model: GreenLab Case. In: Hu, B.G., Jaeger, M., (Eds.), Plant Growth Modeling and Applications. Proceedings PMA03, Tsinghua University Press and Springer, Beijing, China, pp. 87-107.

Sievänen, R., Nikinmaa, E., Nygren, P., Ozier-Lafontaine, H., Perttunen, J., Hakula, H., 2000. Components of functional-structural tree models. Ann. For. Sci. 57, 
399-412.

van Straten, G., Challa, H., Buwalda, F., 2000. Towards user accepted optimal control of greenhouse climate. Computers and Electronics in Agriculture 26, 221-238.

Tardieu, F., 2003. Virtual plants: modelling as a tool for the genomics of tolerance to water deficit. Trends in Plant Science 8, 9-14.

Tripathi, P.K., Bandyopadhyay, S., Pal, S.K., 2007. Multi-Objective Particle Swarm Optimization with time variant inertia and acceleration coefficients. Information Sciences 177, 5033-5049.

Uribelarrea, M., Carcova, J., Otegui, M.E., Westgate, M.E., 2002. Pollen Production, Pollination Dynamics, and Kernel Set in Maize. Crop Sci. 42, 1910-1918.

Vega, C.R.C., Sadras, V.O., Andrade, F.H., Uhart, S.A., 2000. Reproductive Allometry in Soybean, Maize and Sunflower. Annals of Botany 85, 461-468.

Weiner, J., 1988. The influence of competition on plant reproduction. In: Lovett Doust J., Lovett Doust L. (Eds.), Plant reproductive ecology: patterns and strategies, Oxford University Press, New York, pp. 228-245.

Westgate, M.E., Lizaso, J., Batchelor, W., 2003. Quantitative Relationships between Pollen Shed Density and Grain Yield in Maize. Crop Sci. 43, 934-942.

Wu, L., de Reffye, P., Hu, B.G., Le Dimet, F.X., Cournède, P.H., 2005. A Water Supply Optimization Problem for Plant Growth Based on GreenLab Model. ARIMA, 194-207.

Yan, H.P., Kang, M., de Reffye, P., Dingkuhn, M., 2004. A Dynamic, Architectural Plant Model Simulating Resource-dependent Growth. Ann. Bot. 93, 591-602. 
1 Table 1. Estimated parameter values of GreenLab

\begin{tabular}{|c|c|c|}
\hline \multicolumn{2}{|c|}{ Parameters } & Values \\
\hline$P_{a}$ & (Sink strength of blade) & 1 (fixed) \\
\hline$a_{a} / b_{a}$ & (Coefficients of beta function for blade) & $3.59 / 5.38$ \\
\hline$P_{s}$ & (Sink strength of sheath) & 0.6 \\
\hline$a_{s} / b_{s}$ & (Coefficients of beta function for sheath) & $3.05 / 3.69$ \\
\hline$P_{e}$ & (Sink strength of internode) & 1.4 \\
\hline$a_{e} / b_{e}$ & (Coefficients of beta function for internode) & $3.34 / 1.65$ \\
\hline$P_{f}$ & (Sink strength of cob) & 806.47 \\
\hline$a_{f} / b_{f}$ & (Coefficients of beta function for cob) & $8.34 / 2.60$ \\
\hline$P_{m}$ & (Sink strength of tassel) & 4.23 \\
\hline$a_{m} / b_{m}$ & (Coefficients of beta function for tassel) & $1 / 1$ \\
\hline$K_{e}$ & (Coefficient of sink strength for short internode) & 0.21 \\
\hline$\beta$ & (Energetic efficiency) & 12.36 \\
\hline$\gamma$ & (Light interception coefficient) & $1.90 \mathrm{E}-4$ \\
\hline
\end{tabular}




\section{Figure captions}

2 Figure 1. Example of sink variation function (Beta law), with sink strength $P_{o}=10$.

Figure 2. Simulation of biomass partition to (a) blade (b) sheath (c) internode (d) cob (e) tassel, with estimated parameter values by generalized non-linear least square method. "•" represents measured data at the $8^{\text {th }}$ growth cycle corresponding to vegetative stage; “o" measured data at the $18^{\text {th }}$ growth cycle corresponding to flowering stage; “v" measured data at the $33^{\text {rd }}$ growth cycle corresponding to physiological maturity; "-" simulation result at the $8^{\text {th }}$ growth cycle; “...” simulation result at the $18^{\text {th }}$ growth cycle; “...." simulation result at the $33^{\text {rd }}$ growth cycle.

Figure 3. (a) Maximal cob weight associated with cob position (b) Cob sink variations: the curve marked only with symbol represents the corresponding optimal cob sink variation; the curve marked by “-๑-" represents the estimated cob sink variation. Figure 4. Simulation result of leaf area index for maize with estimated parameter values marked by "-•-" and with the optimal one marked by "-○-" where the cob is born by the $1^{\text {st }}$ phytomer counted from the bottom.

Figure 5. Comparison the ratio of cob weight to vegetative compartment weight during the plant growth. “-๑-" represents the result with estimated parameter values and "--০--" represents the result with the optimal parameter values.

Figure 6. Pareto front of the multi-objective optimization problem with respect to cob position on the stem.

1 Figure 7. Area covered by all the optimal cob sink variations associated with the Pareto front. Two examples of the optimal cob sink variations are given. “- $\mathbf{\Delta}="$ 
1 represents the optimal cob sink variation for maize with cob born by the 12th

2 phytomer, where the cob weight is $792 \mathrm{~g}$ and the vegetative compartment is $1695 \mathrm{~g}$;

3 “- $\square$ " the optimal cob sink variation for maize with cob born by the 15th phytomer,

4 where the cob weight is $503 \mathrm{~g}$ and the vegetative compartment is $2050 \mathrm{~g}$.

5 Figure 8. Tassel weight with respect to cob weight, associated with the Pareto front.

6 
1 Appendix

2 Symbol list

$3 Q$ biomass production of an individual plant

$4 \quad Q_{\text {seed }} \quad$ seed biomass

$5 \quad D$ total demand of plant

$6 \quad E$ environmental function

$7 \quad S \quad$ total green leaf surface area

$8 \quad \beta \quad$ energetic efficiency

$9 \quad V$ light inception factor

$10 N_{n}^{o} \quad$ number of organ $o$ born at growth cycle $n$

$11 \mathrm{t}_{\mathrm{x} \_\mathrm{o}}$ expansion duration of organ $o$

12 ta blade functioning duration

$13 \quad p_{o}(j) \quad$ sink value of organ $o$ with age $j$

$14 P_{o}$ sink amplitude (or sink strength) of organ $o$

$15 f$ sink variation function

16 be beta law function

$17 \quad M$ normalization factor

$18 a_{o}$ coefficient of beta law function for organ $o$

$19 b_{o}$ coefficient of beta law function for organ $o$

$20 \Delta q_{o}(n, j)$ biomass increment of organ $o$ with age $j$, when plant age is $n$

$21 q_{o}(n, j)$ accumulated biomass of organ $o$ with age $j$, when plant age is $n$

22 slw specific leaf weight 


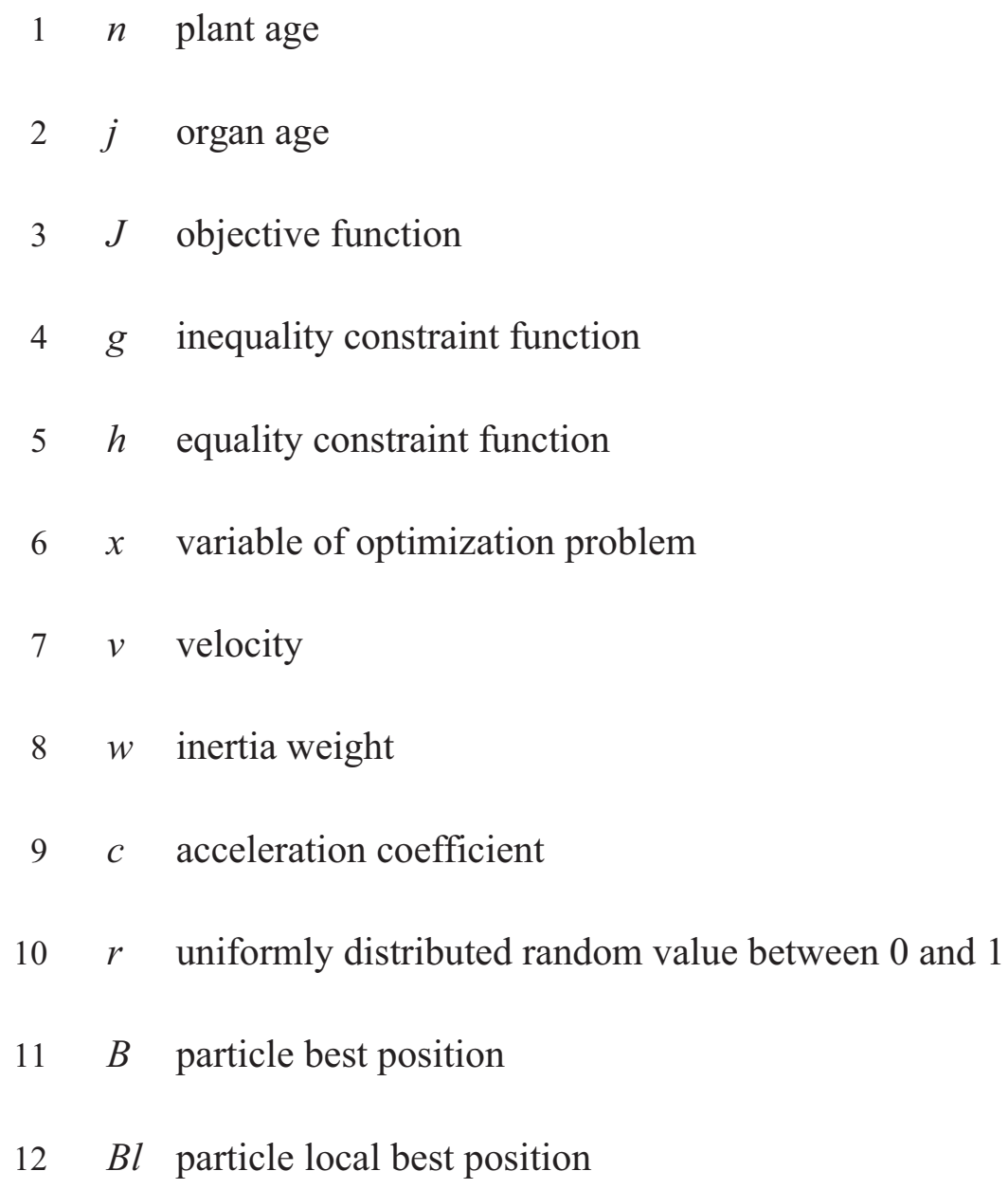


Example of sink variation function (Beta law)

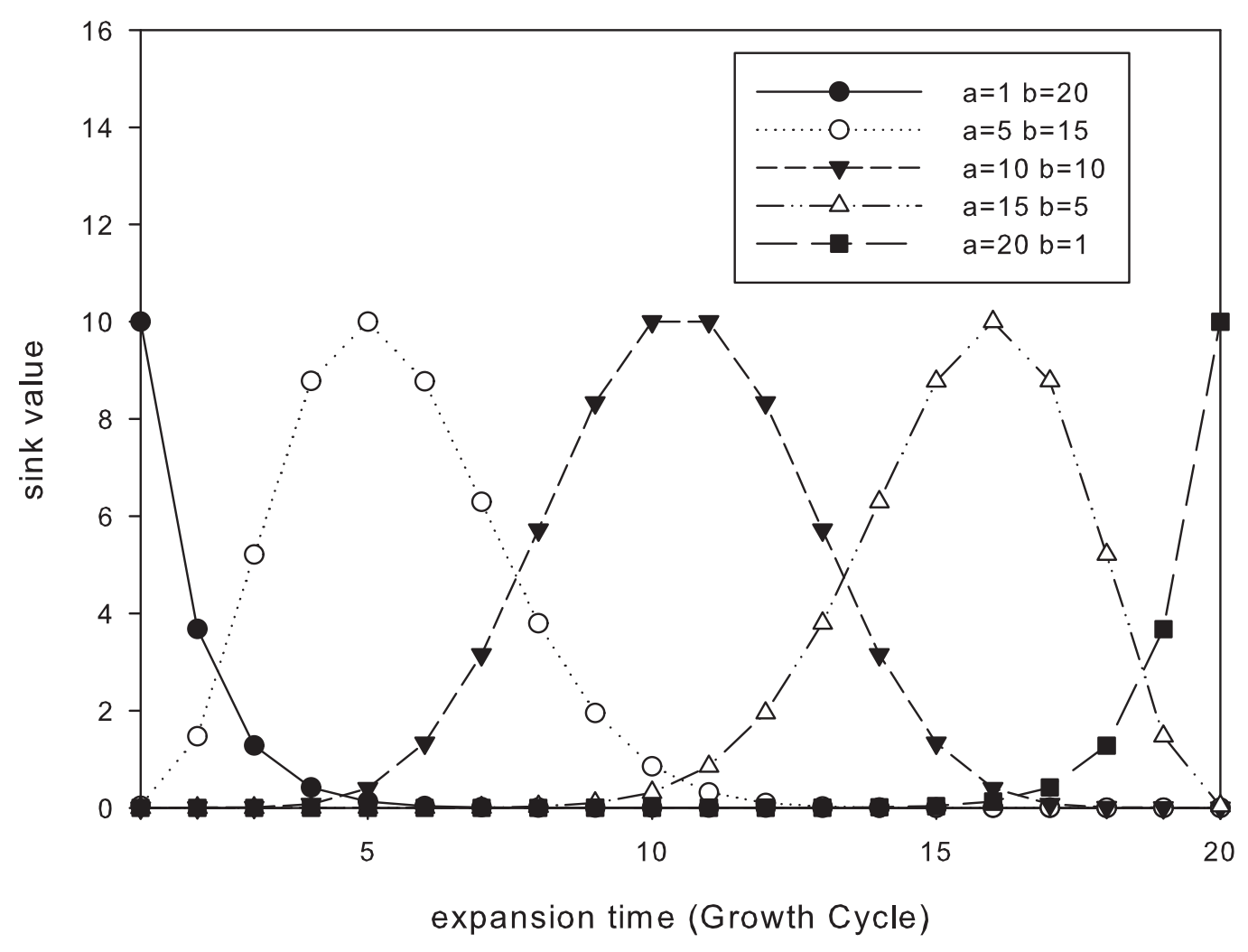


Figure 2(a)

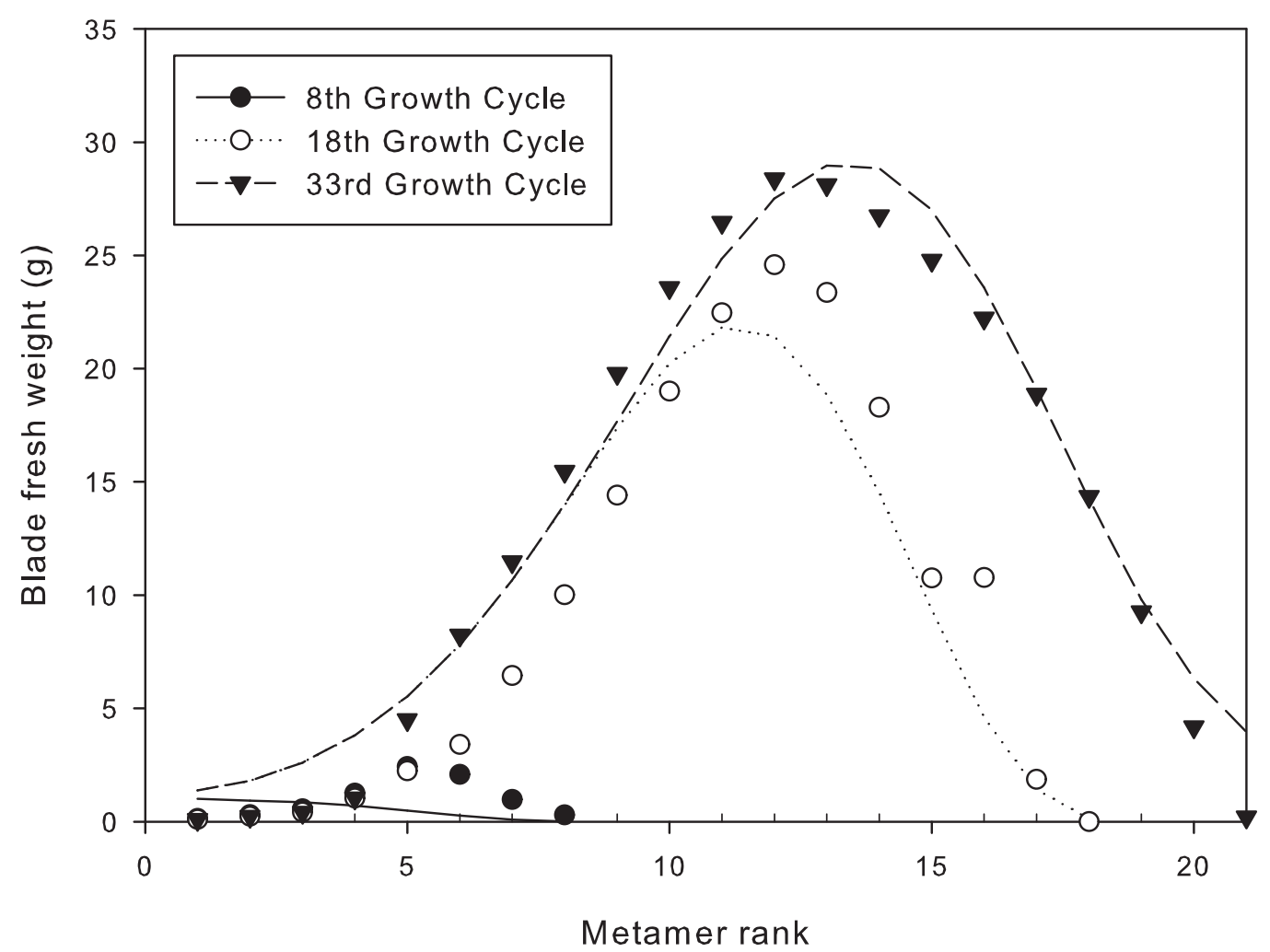


Figure 2(b)

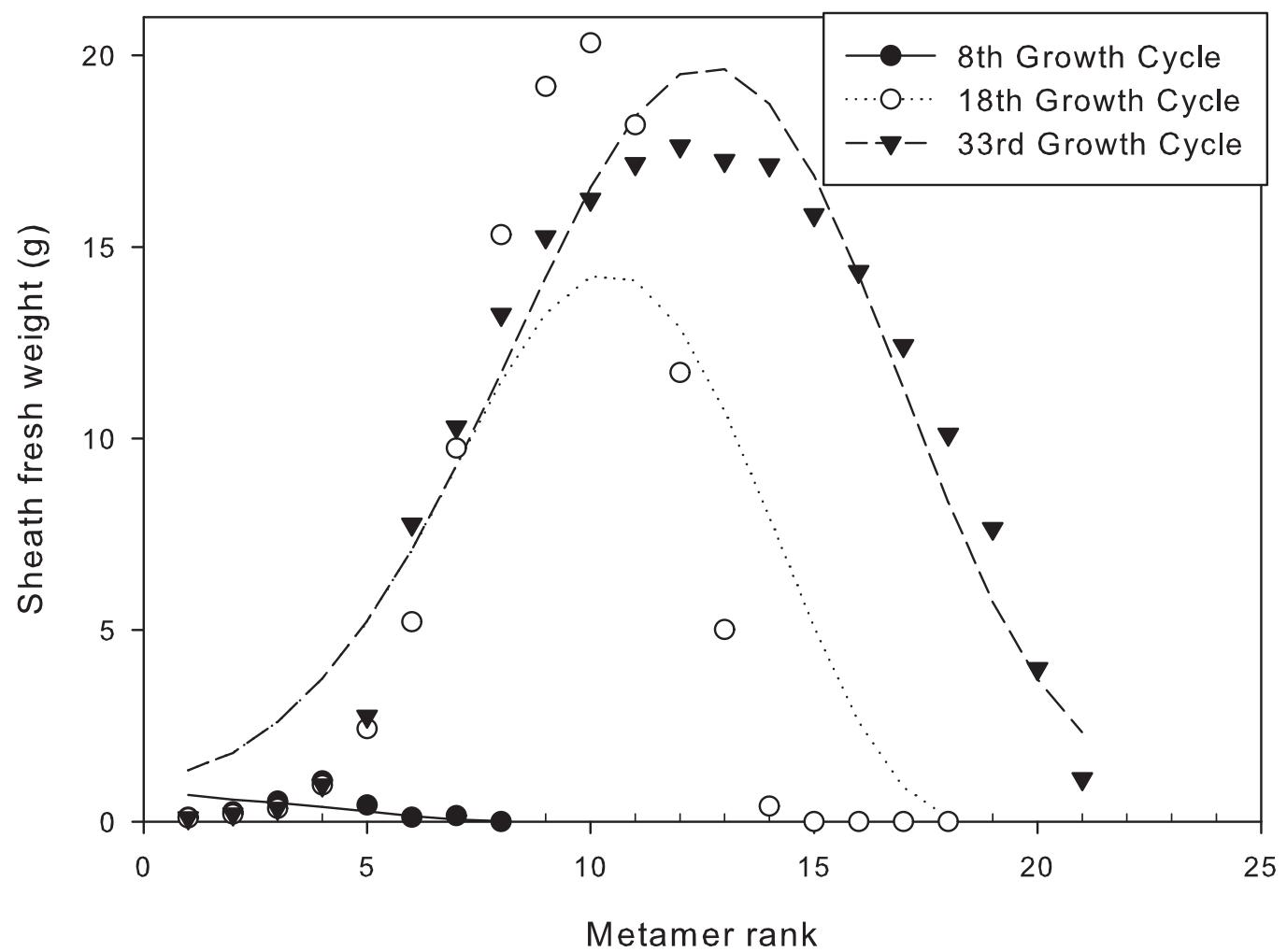


Figure 2(c)

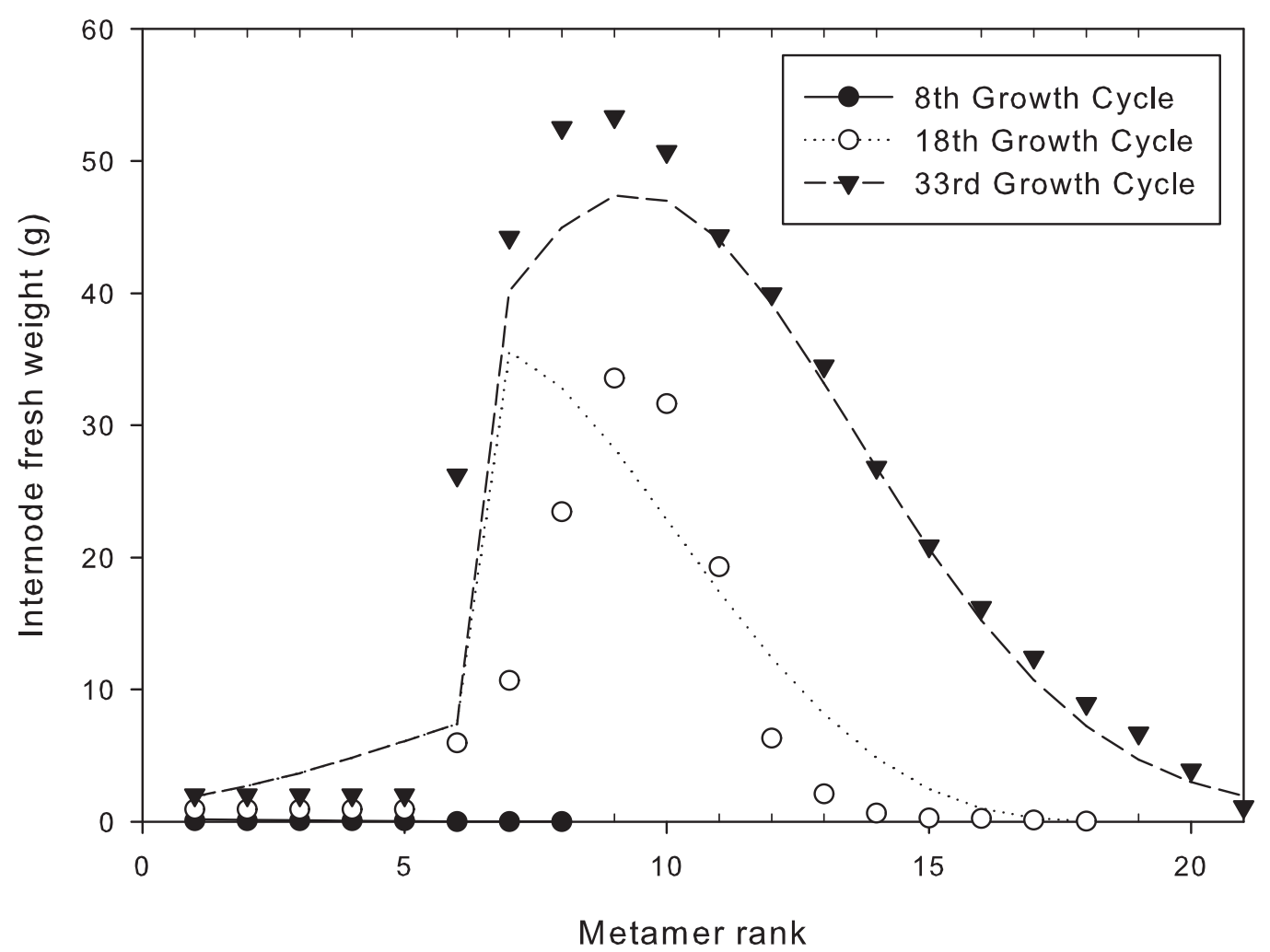


Figure 2(d)

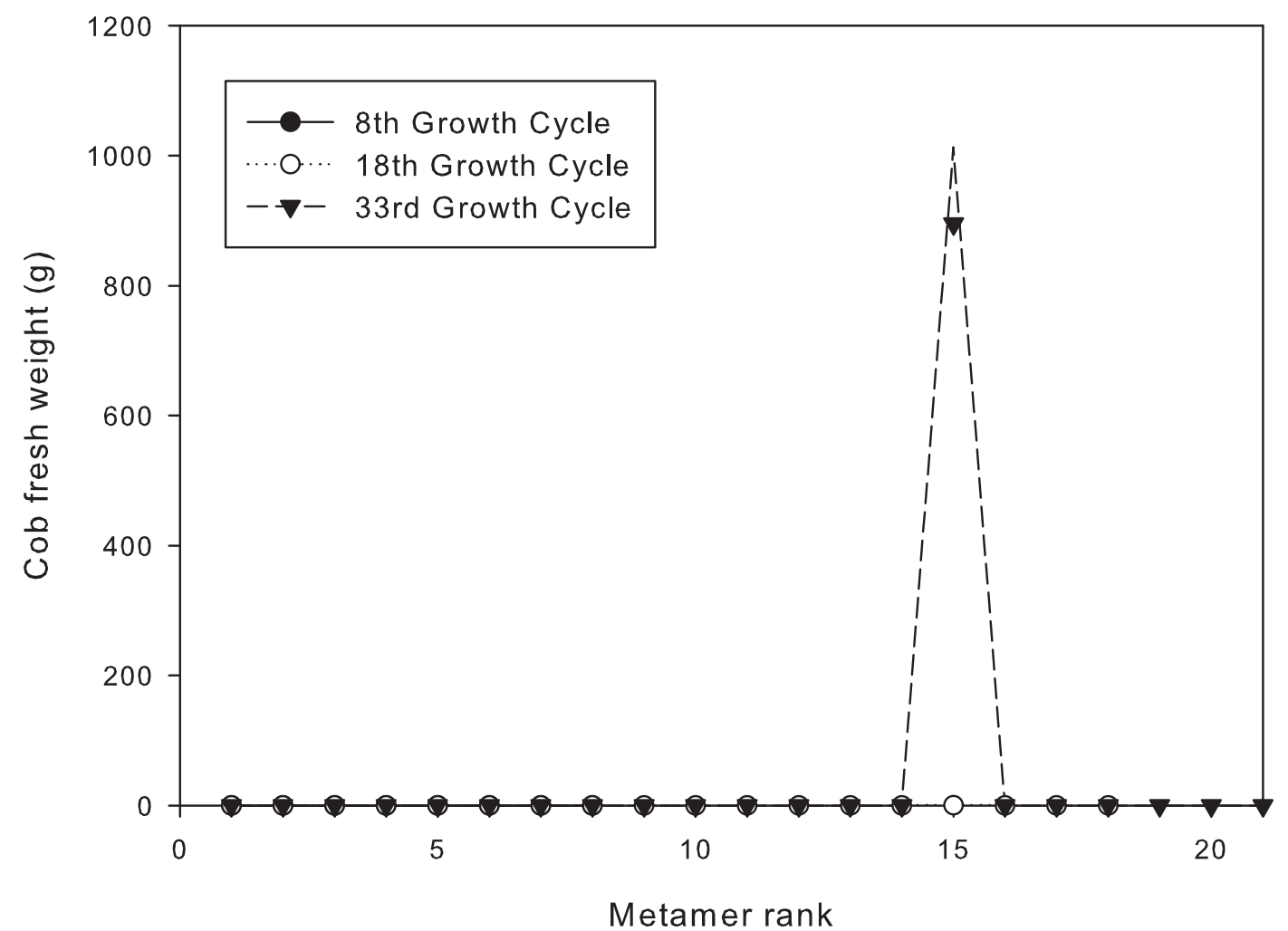


Figure 2(e)

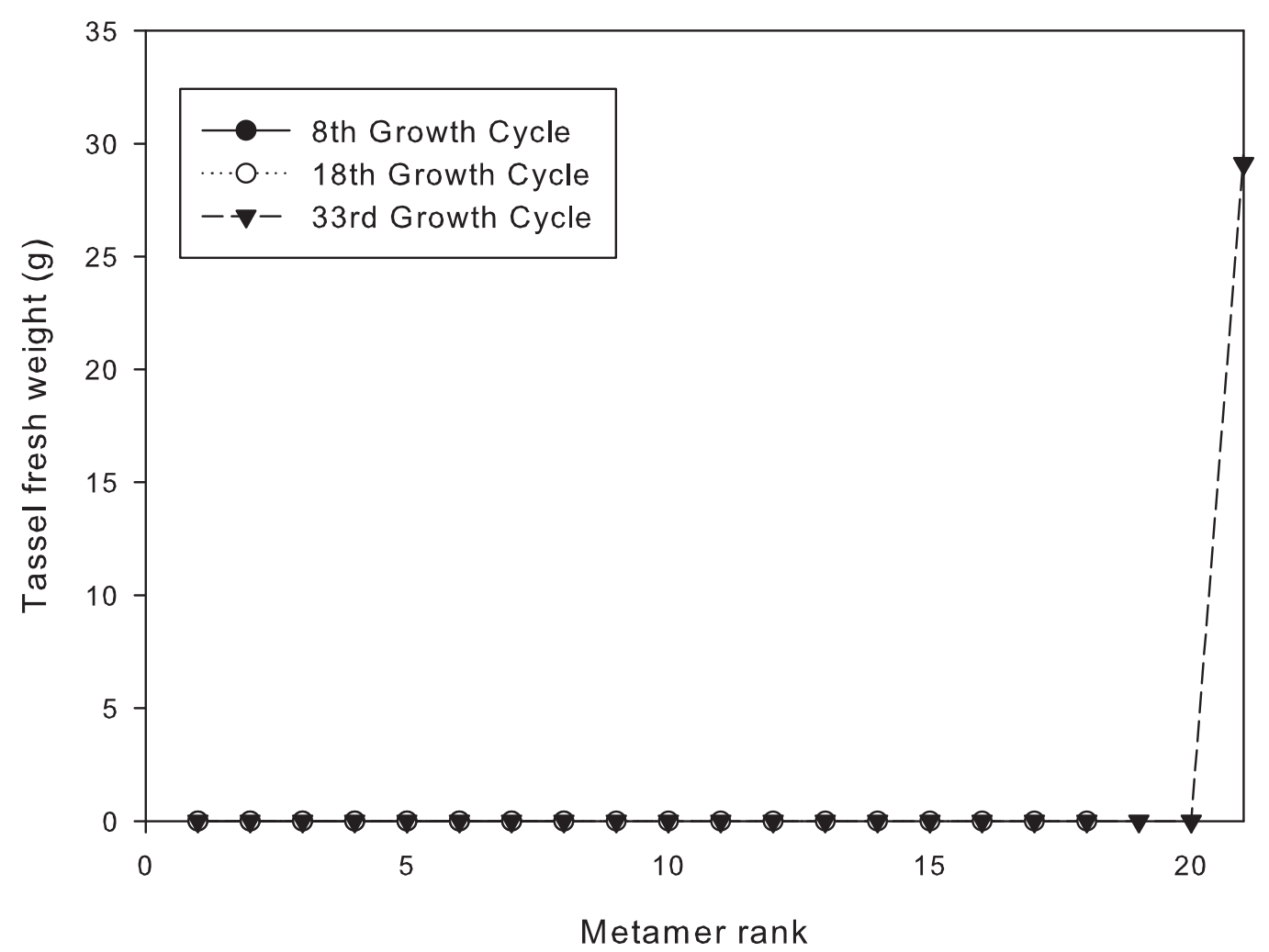


Optimal cob weight associated with cob position

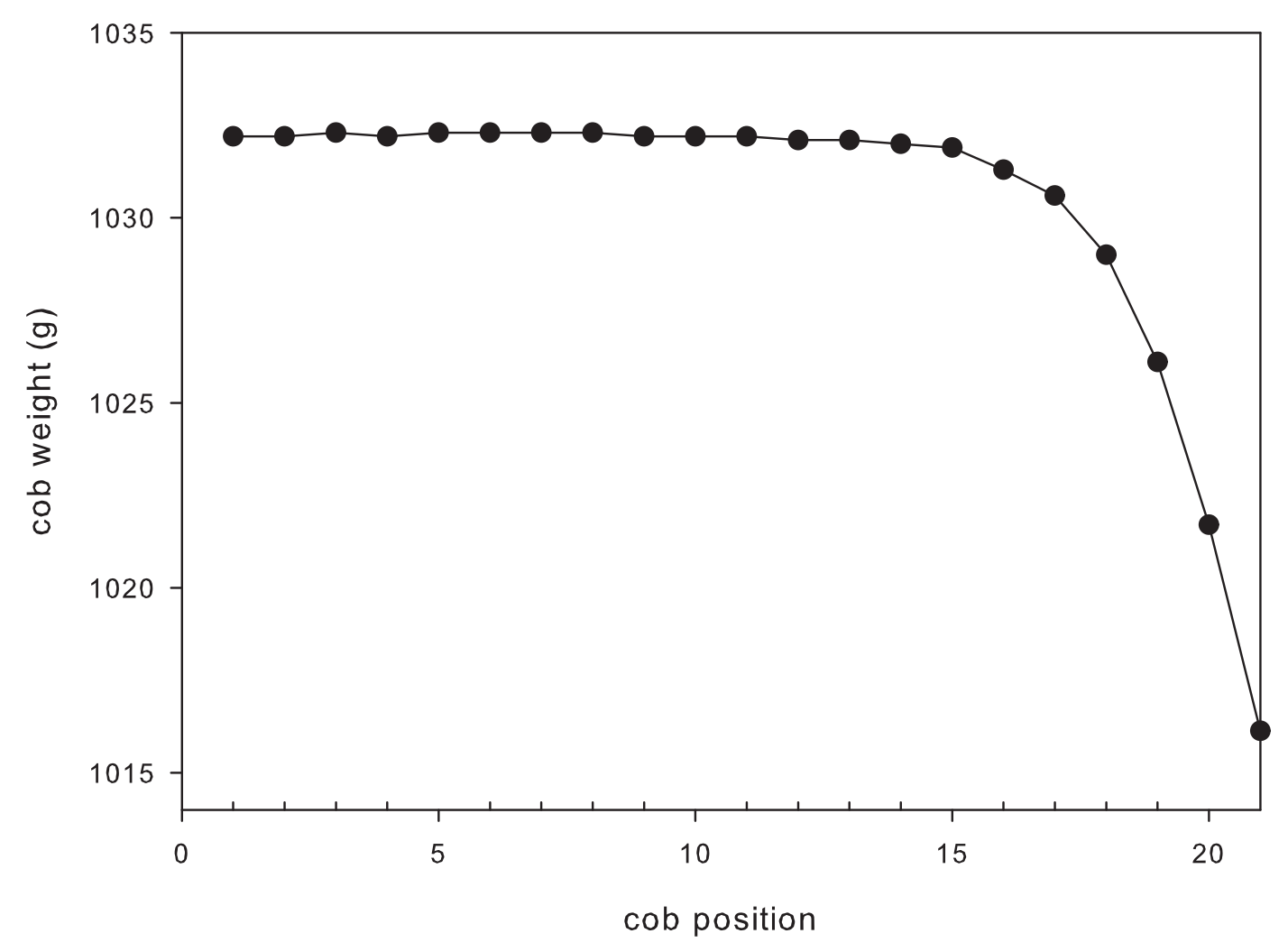


Figure 3(b)

Sink variation

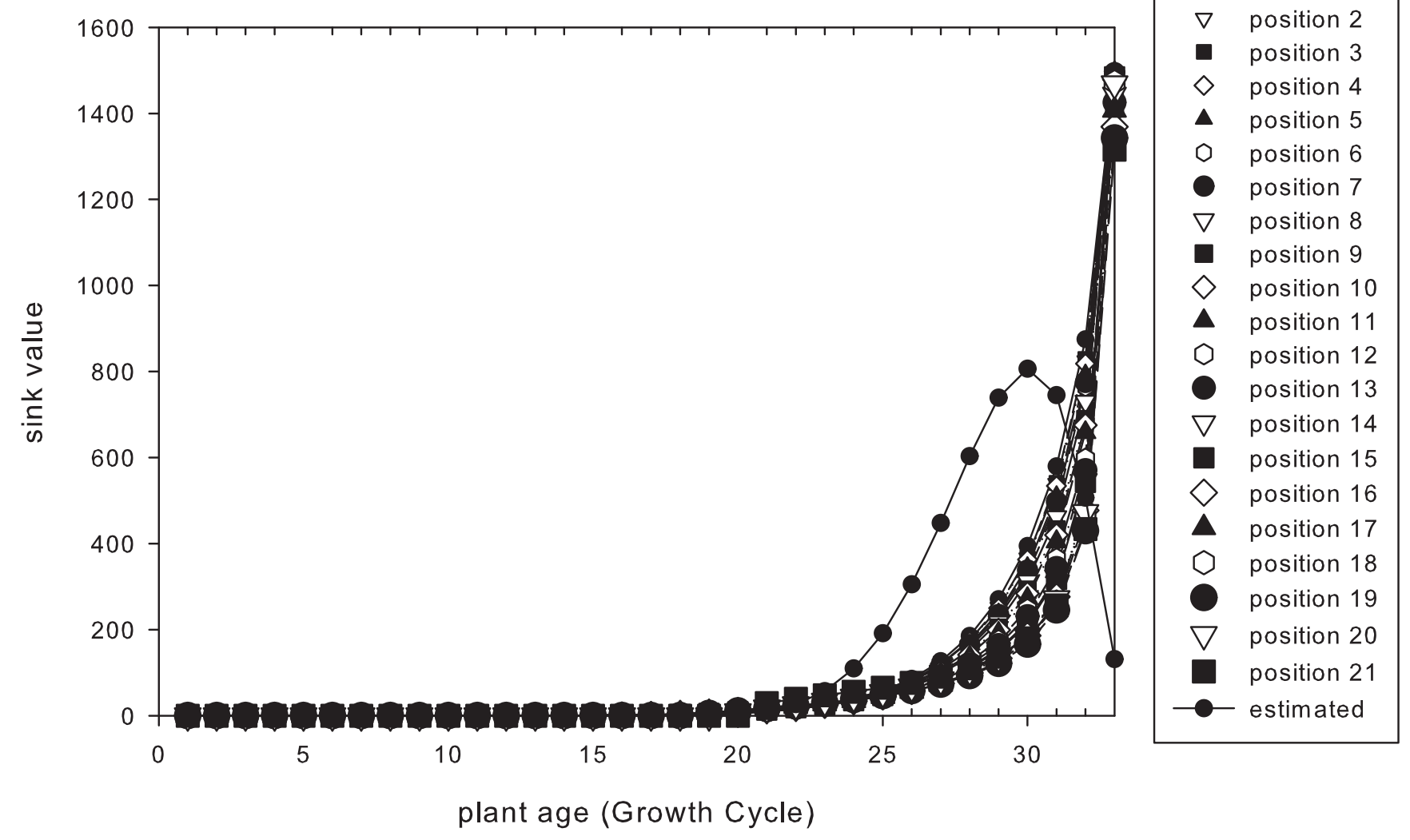


Figure 4

Leaf Area Index (LAI)

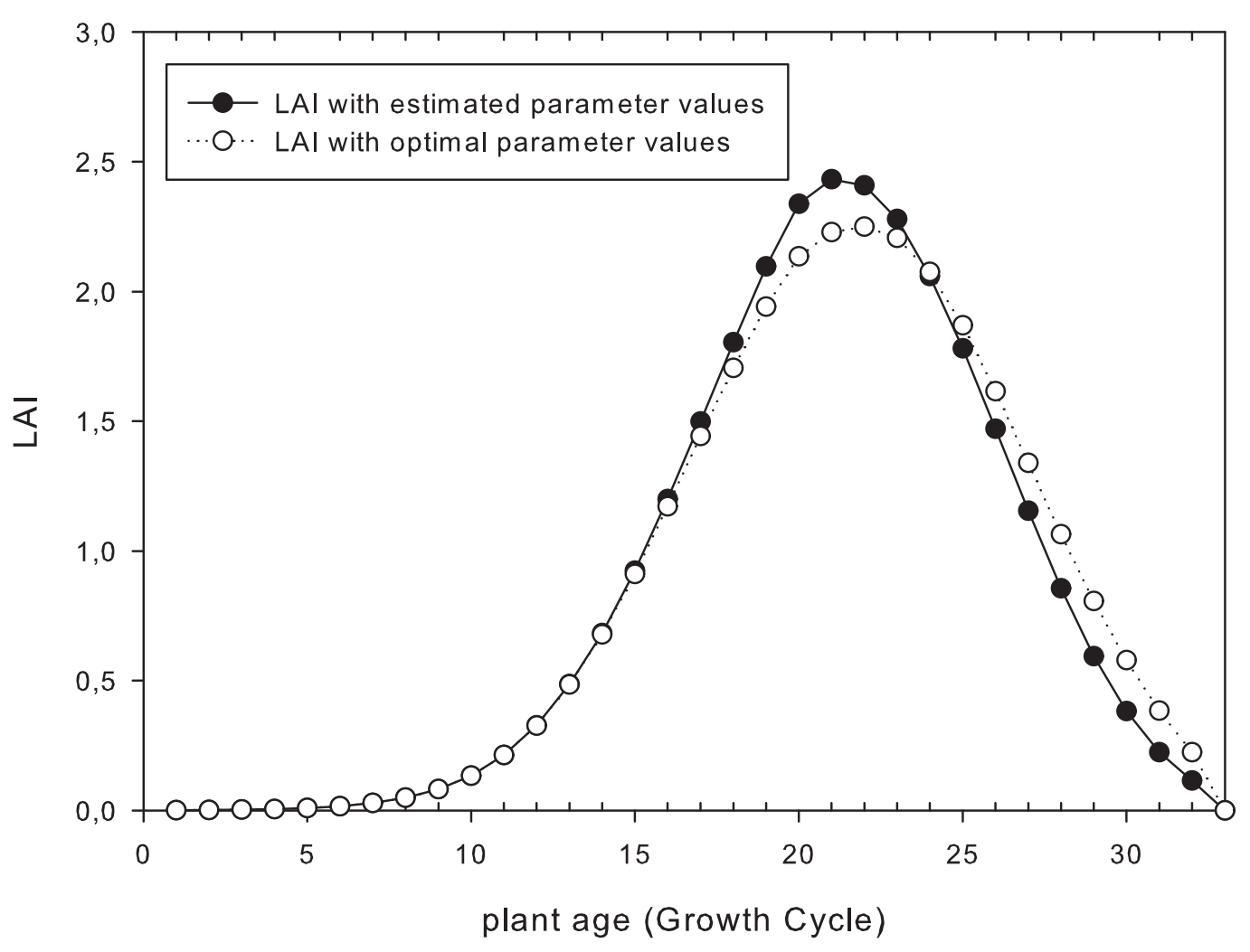


Figure 5

Ratio of cob weight to vegetative compartment weight

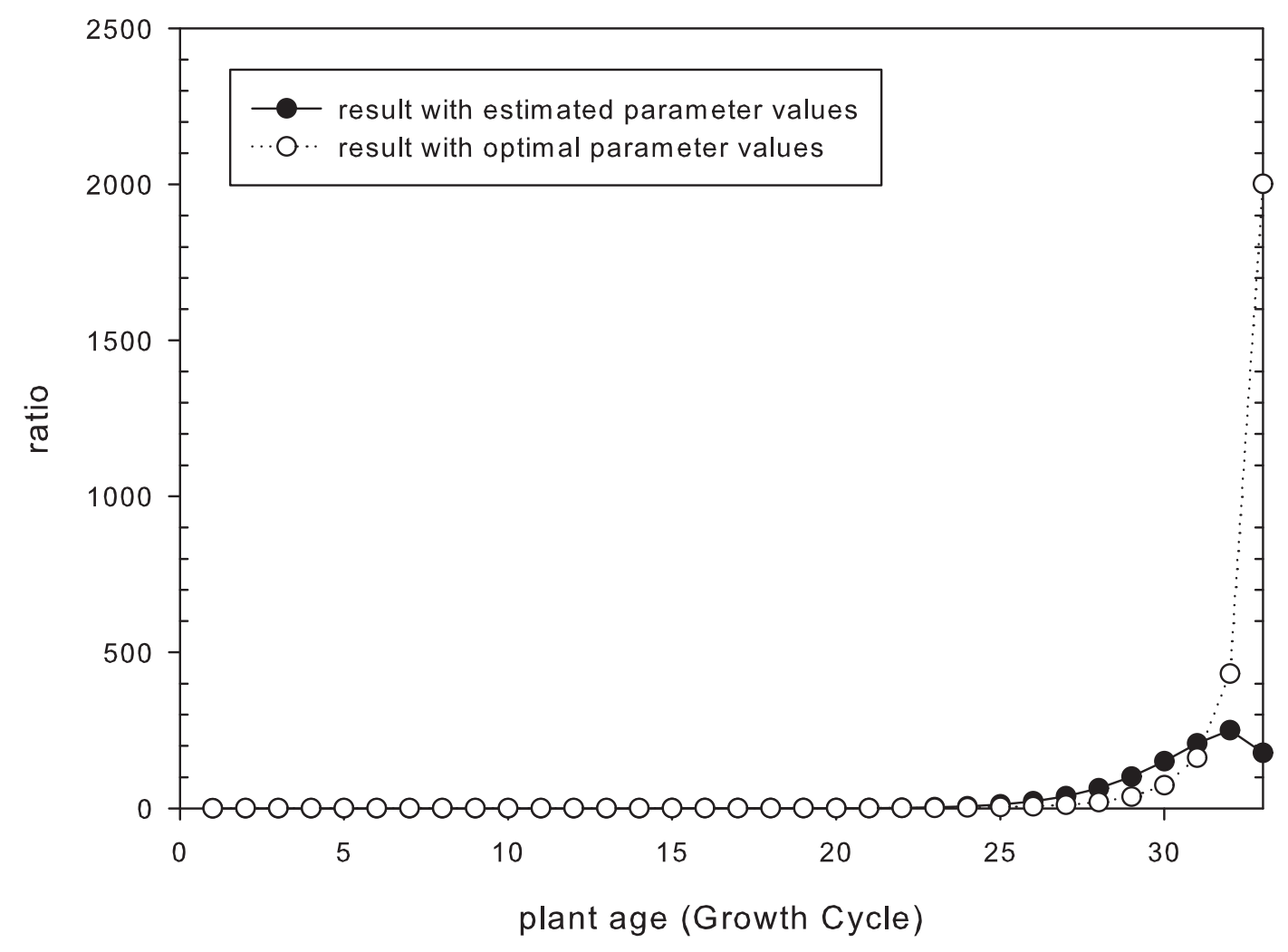


Figure 6

Pareto front

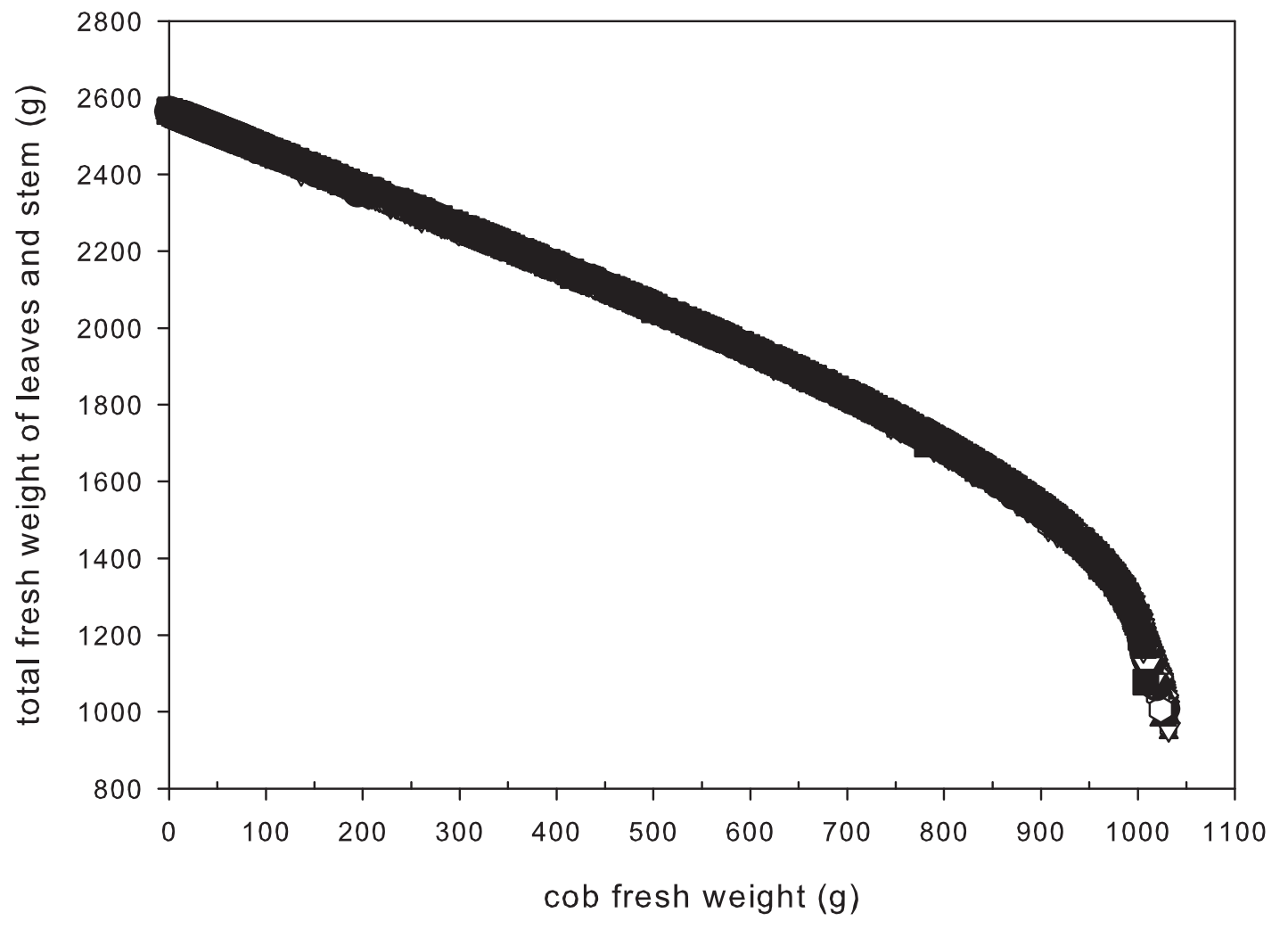

- position 1

$\nabla$ position 2

- position 3

$\diamond$ position 4

- position 5

- position 6

- position 7

$\nabla$ position 8

- position 9

$\diamond$ position 10

- position 11

- position 12

- position 13

$\nabla$ position 14

- position 15

$\diamond$ position 16

- position 17

- position 18

- position 19

$\nabla$ position 20

- position 21

cob fresh weight $(\mathrm{g})$ 
Area covered by all the optimal cob sink variations

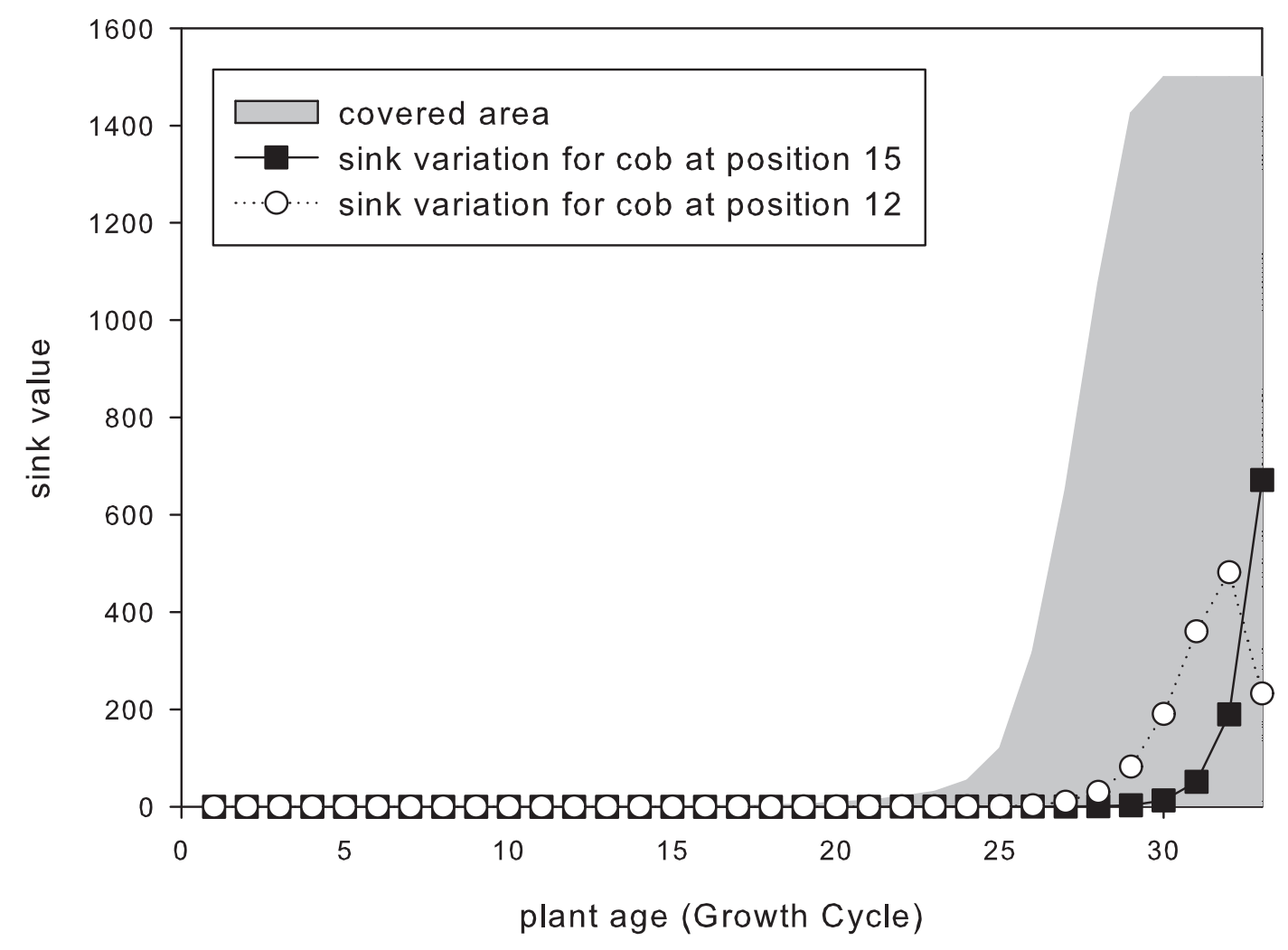


Figure 8

Tassel weight associated with cob weight

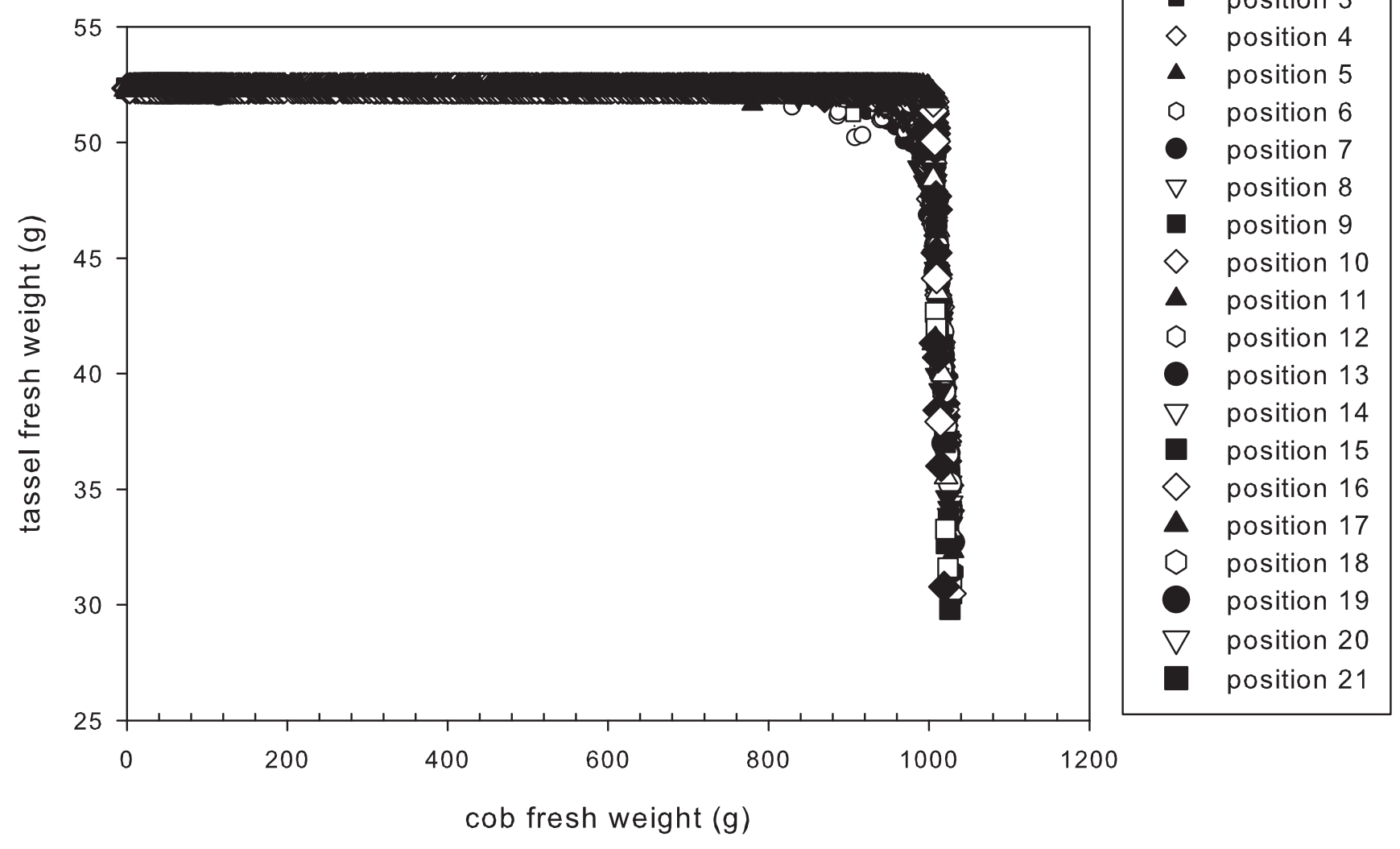

- position 1 $\nabla$ position 2

- position 3

$\diamond$ position 4

- position 5

- position 6

- position 7

$\nabla$ position 8

- position 9

$\diamond$ position 10

- position 11

- position 12

- position 13

$\nabla$ position 14

- position 15

$\diamond$ position 16

- position 17

- position 18

position 19

$\nabla$ position 20

position 21

cob fresh weight (g) 